\title{
Ground-based instruments of the PWING project to investigate dynamics of the inner magnetosphere at subauroral latitudes as a part of the ERG-ground coordinated observation network
}

Kazuo Shiokawa ${ }^{1 *} \mathbb{D}$, Yasuo Katoh', Yoshiyuki Hamaguchi ${ }^{1}$, Yuka Yamamoto ${ }^{1}$, Takumi Adachi ${ }^{1}$, Mitsunori Ozaki ${ }^{2}$, Shin-Ichiro Oyama', Masahito Nosé3, Tsutomu Nagatsuma ${ }^{4}$, Yoshimasa Tanaka ${ }^{5}$, Yuichi Otsuka', Yoshizumi Miyoshi', Ryuho Kataoka ${ }^{5}$, Yuki Takagi ${ }^{1}$, Yuhei Takeshita', Atsuki Shinbori', Satoshi Kurita', Tomoaki Hori ${ }^{1}$, Nozomu Nishitani ${ }^{1}$, Iku Shinohara ${ }^{6}$, Fuminori Tsuchiya ${ }^{7}$, Yuki Obana ${ }^{8}$, Shin Suzuki ${ }^{9}$, Naoko Takahashi ${ }^{10}$, Kanako Seki $^{10}$, Akira Kadokura ${ }^{5}$, Keisuke Hosokawa $^{11}$, Yasunobu Ogawa ${ }^{5}$, Martin Connors ${ }^{12}$, J. Michael Ruohoniemi ${ }^{13}$, Mark Engebretson ${ }^{14}$, Esa Turunen ${ }^{15}$, Thomas Ulich ${ }^{15}$, Jyrki Manninen ${ }^{15}$, Tero Raita ${ }^{15}$, Antti Kero ${ }^{15}$, Arto Oksanen ${ }^{16}$, Marko Back ${ }^{16}$, Kirsti Kauristie ${ }^{17}$, Jyrki Mattanen ${ }^{17}$, Dmitry Baishev ${ }^{18}$, Vladimir Kurkin ${ }^{19}$, Alexey Oinats ${ }^{19}$, Alexander Pashinin ${ }^{19}$, Roman Vasilyev $^{19}$, Ravil Rakhmatulin ${ }^{19}$, William Bristow ${ }^{20}$ and Marty Karjala ${ }^{20}$

\begin{abstract}
The plasmas (electrons and ions) in the inner magnetosphere have wide energy ranges from electron volts to megaelectron volts $(\mathrm{MeV})$. These plasmas rotate around the Earth longitudinally due to the gradient and curvature of the geomagnetic field and by the co-rotation motion with timescales from several tens of hours to less than $10 \mathrm{~min}$. They interact with plasma waves at frequencies of $\mathrm{mHz}$ to $\mathrm{kHz}$ mainly in the equatorial plane of the magnetosphere, obtain energies up to $\mathrm{MeV}$, and are lost into the ionosphere. In order to provide the global distribution and quantitative evaluation of the dynamical variation of these plasmas and waves in the inner magnetosphere, the PWING project (study of dynamical variation of particles and waves in the inner magnetosphere using ground-based network observations, http://www.isee.nagoya-u.ac.jp/dimr/PWING/) has been carried out since April 2016. This paper describes the stations and instrumentation of the PWING project. We operate all-sky airglow/aurora imagers, 64-Hz sampling induction magnetometers, 40-kHz sampling loop antennas, and $64-\mathrm{Hz}$ sampling riometers at eight stations at subauroral latitudes $\left(\sim 60^{\circ}\right.$ geomagnetic latitude) in the northern hemisphere, as well as $100-\mathrm{Hz}$ sampling EMCCD cameras at three stations. These stations are distributed longitudinally in Canada, Iceland, Finland, Russia, and Alaska to obtain the longitudinal distribution of plasmas and waves in the inner magnetosphere. This PWING longitudinal network has been developed as a part of the ERG (Arase)-ground coordinated observation network. The ERG (Arase) satellite was launched on December 20, 2016, and has been in full operation since March 2017. We will combine these ground network observations with the ERG (Arase) satellite and global modeling studies. These comprehensive datasets will
\end{abstract}

\footnotetext{
*Correspondence: shiokawa@nagoya-u.jp

${ }^{1}$ Institute for Space-Earth Environmental Research, Nagoya University,

Nagoya 464-8601, Japan

Full list of author information is available at the end of the article
} 
contribute to the investigation of dynamical variation of particles and waves in the inner magnetosphere, which is one of the most important research topics in recent space physics, and the outcome of our research will improve safe and secure use of geospace around the Earth.

Keywords: All-sky airglow/aurora imager, Induction magnetometer, Riometer, Loop antenna, EMCCD camera, Inner magnetosphere, SAR arc, Magnetospheric ELFNLF wave, EMIC wave, Radiation belts

\section{Introduction}

The inner magnetosphere is a key region of the Earth's magnetosphere to understand dynamical variations of plasma and electromagnetic fields and their connection to the ionosphere and atmosphere. This region contains both the highest and lowest energy plasmas in the Earth's magnetosphere, i.e., electrons with energies more than mega-electronvolts $(\mathrm{MeV})$ in the radiation belts (e.g., Baker et al. 1986) and plasmas (electrons and ions) with energies less than one electronvolt $(\mathrm{eV})$ in the plasmasphere (e.g., Carpenter 1966). The processes that cause acceleration of electrons to energies of $\mathrm{MeV}$ are still not clear. The injection of plasma-sheet particles to the inner magnetosphere causes betatron acceleration, which is not sufficient to create $\mathrm{MeV}$ electrons (e.g., Reeves et al. 2013). One of the major acceleration processes to create $\mathrm{MeV}$ electrons is the interaction between plasma waves and electrons (e.g., Summers et al. 1998; Miyoshi et al. 2003; Omura et al. 2007). The wave-particle interaction also contributes to the loss of the electrons and ions to the atmosphere (e.g., Abel and Thorne 1998; Summers and Thorne 2003; Shoji and Omura 2012). Both electron cyclotron waves with frequencies on the order of $\mathrm{kHz}$ [at extremely low frequency (ELF)/very low frequency (VLF) range] and electromagnetic ion cyclotron (EMIC) waves with frequencies on the order of $\mathrm{Hz}$ (ULF range) contribute to these acceleration and loss of the electrons and ions in the inner magnetosphere. In addition, Pc 5 geomagnetic pulsations with frequencies at $\mathrm{mHz}$ also contribute to the acceleration and loss of plasmas through drift-bounce resonance (e.g., Elkington et al. 1999).

The high-energy plasmas drift around the Earth with timescales of hours to tens of minutes due to gradient and curvature of the magnetic field. On the other hand, the electron-cyclotron (ELF/VLF) waves and EMIC waves are localized mainly in the dusk and dawn sectors, respectively (e.g., Li et al. 2011; Wang et al. 2015). Thus, observations of longitudinal distribution of these waves and drifting plasmas are essentially important to understand particle energization and loss in the inner magnetosphere quantitatively. One can obtain longitudinal distribution of waves and particles through statistical analyses of long-term single satellite data by using its orbital motion. However, instantaneous measurement of the longitudinal distribution of waves and particles is essential to provide quantitative understanding, because, for example, statistical analysis of long-term single satellite data can lead to misinterpreting a moving localized wave source as a wide spatial extent of the source region. However, multi-point measurements in the equatorial plane of the magnetosphere are difficult due to the limited number of satellites exploring this region in situ.

The particles and waves in the inner magnetosphere can be monitored from ground-based instruments installed at subauroral latitudes, because charged particles and waves basically propagate along geomagnetic field lines. Such a longitudinal ground-based network at subauroral latitudes has not been developed previously. We started a new project called the PWING project (study of dynamical variation of particles and waves in the inner magnetosphere using ground-based network observations) in April 2016. The PWING project provides a longitudinal network of ground-based instruments that monitor ULF/ELF/VLF waves and high- and low-energy plasmas at eight stations at geomagnetic latitudes (MLATs) of $\sim 60^{\circ}$ in the northern hemisphere. The $60^{\circ}$ MLAT was chosen because it is connected to the magnetic field line of $L=4$ which is the key radial distance to study the wave-particle interaction in the vicinity of the plasmapause. In this paper, we show details of ground-based instruments developed by the PWING project, which are all-sky airglow/aurora imagers, induction magnetometers, loop antennas, riometers, and electron-multiplying charge-coupled device (EMCCD) cameras. By combining these ground-based network measurements with in situ measurements of plasma and waves by the Arase and Van Allen Probes satellites (Miyoshi et al. 2017a, this issue; Mauk et al. 2013) and with global modeling of particles and waves (Seki et al. 2017, this issue), quantitative understanding of particle acceleration and loss in the inner magnetosphere will become possible. The quantitative understanding of highenergy particle dynamics in the inner magnetosphere also contributes to improvement of space weather forecast for practical use of geospace, because the existence of highenergy particles is one of the major causes of spacecraft anomalies (e.g., Baker 2000).

\section{Overview of the stations and instruments}

Table 1 shows the geographic and geomagnetic coordinates, instruments, and collaborators of the stations 
Table 1 Geographic and geomagnetic coordinates of the PWING stations, instruments with their start dates in year/ month/day (yymmdd), and local collaborators

\begin{tabular}{|c|c|c|c|c|c|c|c|c|c|c|}
\hline Station & Country & Abbreviation & Geographic latitu & ude (N) & Geograp & hic longitude (E) & MLAT (N) & MLON (E) & $L$ value & UT of zero MLT \\
\hline Nyrölä & Finland & NYR & 62.34 & & 25.51 & & 59.0 & 103.2 & 3.8 & 21.4 UT \\
\hline Istok & Russia & IST & 70.03 & & 88.01 & & 65.9 & 162.6 & 6.0 & 18.0 UT \\
\hline Zhigansk & Russia & ZGN & 66.78 & & 123.37 & & 61.9 & 195.7 & 4.5 & 16.2 UT \\
\hline Maimaga & Russia & MAM & 63.06 & & 129.56 & & 58.0 & 202.0 & 3.6 & 15.8 UT \\
\hline Gakona & USA & GAK & 62.39 & & 214.78 & & 63.2 & 271.0 & 4.9 & 10.7 UT \\
\hline Athabasca & Canada & ATH & 54.60 & & 246.36 & & 61.5 & 308.3 & 4.4 & 8.1 UT \\
\hline Kapuskasing & Canada & KAP & 49.39 & & 277.81 & & 59.0 & 353.4 & 3.8 & 5.5 UT \\
\hline Nain & Canada & $\mathrm{NAl}$ & 56.50 & & 298.30 & & 63.4 & 22.4 & 5.0 & 3.7 UT \\
\hline Husafell & Iceland & HUS & 64.67 & & 338.97 & & 64.9 & 66.5 & 5.6 & 0.3 UT \\
\hline Kevo & Finland & KEV & 69.76 & & 27.01 & & 66.7 & 108.4 & 6.4 & 21.1 UT \\
\hline Station & Country & Abbreviation & All-sky imager & $\begin{array}{l}\text { Induct } \\
\text { netom }\end{array}$ & $\begin{array}{l}\text { ion mag- } \\
\text { eter }\end{array}$ & Riometer & Loop ante & EMC & CD camera & a Collaborator \\
\hline Nyrölä & Finland & NYR & $\begin{array}{l}\text { PWING (C18 (CI)) } \\
170124-\end{array}$ & $\begin{array}{l}\mathrm{SGO}(\wedge \\
\text { pree }\end{array}$ & $\begin{array}{l}\text { UR) } \\
\text { kisting }\end{array}$ & $\begin{array}{l}\mathrm{SGO}(J \mathrm{YV}) \\
\text { preexisting }\end{array}$ & $\begin{array}{r}\text { SGO (KAN) } \\
\text { preexistir }\end{array}$ & & & FMI \\
\hline Istok & Russia & IST & $\begin{array}{l}\text { PWING (C20 } \\
\text { (CK)) 171029- }\end{array}$ & $\begin{array}{l}\text { ISTP }(\mathrm{LI} \\
\text { pree> }\end{array}$ & $\begin{array}{l}\text { EMl-30) } \\
\text { xisting }\end{array}$ & $\begin{array}{l}\text { PWING (RIO03) } \\
171029-\end{array}$ & $\begin{array}{l}\text { PWING (VL } \\
171029-\end{array}$ & & & ISTP \\
\hline Zhigansk & Russia & ZGN & $\begin{array}{l}\text { PWING (C14(CE)) } \\
\text { TBD }\end{array}$ & PWING & $160914-$ & $\begin{array}{l}\text { PWING (RIO06) } \\
170927-\end{array}$ & & & & IKFIA \\
\hline Maimaga & Russia & MAM & & & & & $\begin{array}{l}\text { PWING (VL } \\
170418-\end{array}$ & & & IKFIA \\
\hline Gakona & USA & GAK & $\begin{array}{l}\text { PWING (C19 (CJ)) } \\
170303-\end{array}$ & $\begin{array}{r}\text { PWING } \\
\quad \text { amp } \\
1703\end{array}$ & $\begin{array}{l}\text { 002) } \\
\text { 03- }\end{array}$ & $\begin{array}{l}\text { PWING (RIO04) } \\
170109-\end{array}$ & $\begin{array}{c}\text { PWING (VL } \\
170929-\end{array}$ & PWII & JG 170303- & $\begin{array}{l}\text { GI-UAF, Univ. } \\
\text { Florida }\end{array}$ \\
\hline Athabasca & Canada & ATH & $\begin{array}{c}\text { PWING (C7) } \\
\text { 050903- }\end{array}$ & PWING & $050907-$ & $\begin{array}{l}\text { PWING (RIO01) } \\
161025-\end{array}$ & $\begin{array}{c}\text { PWING (VL } \\
120219-\end{array}$ & 01) & JG 120924- & $\begin{array}{l}\text { Athabasca } \\
\text { Univ. }\end{array}$ \\
\hline Kapuskasing & Canada & KAP & $\begin{array}{l}\text { PWING (C16 } \\
\text { (CG)) 170225- }\end{array}$ & $\begin{array}{r}\text { PWING } \\
\text { (amp } \\
1612\end{array}$ & $\begin{array}{l}\text { 001) } \\
14-\end{array}$ & $\begin{array}{l}\text { PWING (RIO02) } \\
170224-\end{array}$ & $\begin{array}{l}\text { PWING (VL } \\
161212-\end{array}$ & & & Virginia Tech. \\
\hline Nain & Canada & $\mathrm{NAl}$ & $\begin{array}{c}\text { PWING (C17 } \\
(\mathrm{CH})) \text { TBD }\end{array}$ & $\begin{array}{r}\text { PWING } \\
\quad(a m p\end{array}$ & 003) TBD & PWING TBD & $\begin{array}{l}\text { PWING (VL } \\
\text { TBD }\end{array}$ & & & $\begin{array}{c}\text { Augsburg } \\
\text { College }\end{array}$ \\
\hline Husafell & Iceland & HUS & $\begin{array}{l}\text { PWING (C21 } \\
\text { (CL)) 170321- }\end{array}$ & NIPR p & reexisting & $\begin{array}{l}\text { NIPR (RIO05) } \\
\text { preexisting }\end{array}$ & NIPR preex & isting & & $\begin{array}{l}\text { NIPR, Univ. } \\
\text { Iceland }\end{array}$ \\
\hline Kevo & Finland & KEV & & & & & & PWII & JG 170127- & FMI \\
\hline
\end{tabular}

FMI Finnish Meteorological Institute, ISTP Institute of Solar-Terrestrial Physics, Siberian Branch of the Russian Academy of Sciences, Russian Federation, IKFIA Yu.G. Shafer Institute of Cosmophysical Research and Aeronomy, Siberian Branch of the Russian Academy of Sciences, Russian Federation, GI-UAF Geophysical Institute, University of Alaska Fairbanks, NIPR National Institute of Polar Research, Japan, SGO Sodankylä Geophysical Observatory, NUR Nurmijärvi, JYV Jyväskylä, KAN Kannuslehto, TBD to be determined, magnetic latitudes (MLAT), magnetic longitudes (MLON), $L$ value, and UT at zero MLT are calculated by the Corrected Geomagnetic Coordinates (CGM) by https://omniweb.gsfc.nasa.gov/vitmo/cgm_vitmo.html at an altitude of $100 \mathrm{~km}$

newly deployed by the PWING project. The magnetic latitudes (MLAT), magnetic longitudes (MLON), $L$ values, and UT at zero magnetic local time (MLT) are calculated using corrected geomagnetic coordinates (CGM) by https://omniweb.gsfc.nasa.gov/vitmo/cgm_vitmo. html at an altitude of $100 \mathrm{~km}$. Figure 1 shows the locations of these stations in MLT-MLAT maps. The PWING project deploys four instruments, i.e., all-sky airglow/ aurora imagers, induction magnetometers, broad-beam riometers, and loop antennas, at eight stations. EMCCD cameras with a sampling rate of $100 \mathrm{~Hz}$ are also installed at three stations. At some stations, we share data of preexisting instruments operated by local institutions. The dates of the start of automatic operation of the instruments are shown in a year/month/day (yymmdd) format. All these instruments had started their automatic operations before March 22, 2017, except for the instruments at Nain, and the all-sky imagers, riometers, and loop antennas at two Russian stations.

In the longitude of Finland, we deploy an all-sky airglow/aurora imager at Nyrölä (NYR) in collaboration with the Finnish Meteorological Institute (FMI), while other instruments have already been operated by the Sodankylä Geophysical Observatory (SGO, http://www. 


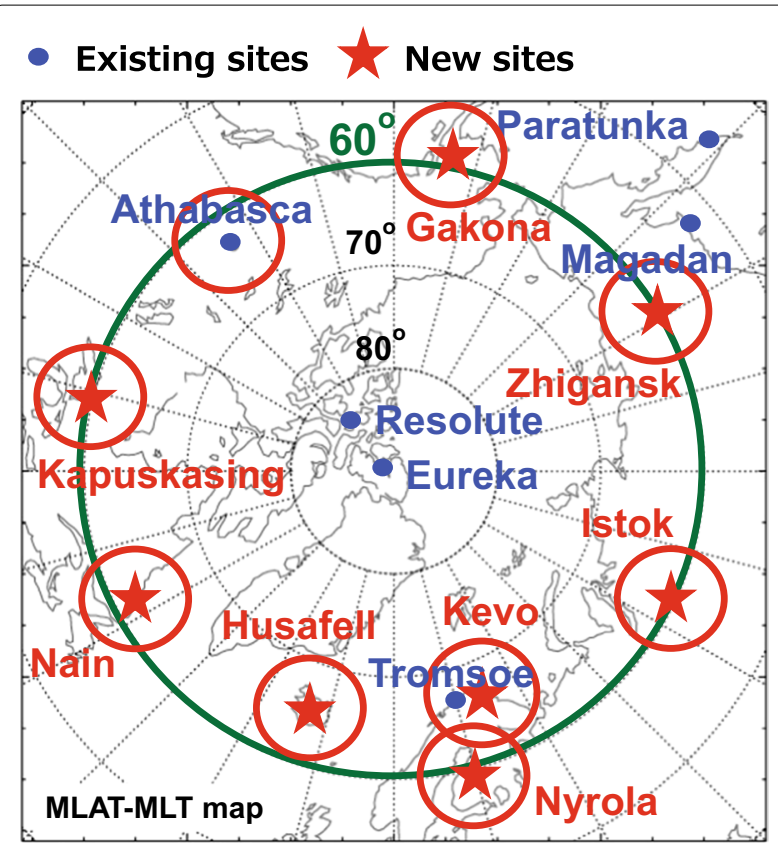

Fig. 1 PWING stations in the magnetic local time-magnetic latitude map. Blue dots and red stars indicate preexisting and new sites deployed by the PWING project, respectively. The red circles indicate rough area of the field of view of all-sky imager

sgo.fi/) at nearby stations. Istok (IST) is a remote station which is $\sim 100 \mathrm{~km}$ north of the nearest city Norilsk in Russia. The Institute of Solar-Terrestrial Physics (ISTP), Siberian Branch of the Russian Academy of Sciences, Russian Federation, operated an induction magnetometer and auroral cameras in a container house at Istok, while the PWING installed another container house to install other instruments. Zhigansk (ZGN) is an observatory operated by the Yu.G. Shafer Institute of Cosmophysical Research and Aeronomy (IKFIA), Siberian Branch of the Russian Academy of Sciences, Russian Federation. Since the ZGN observatory is close to an airport facility where high electromagnetic noise is expected, the loop antenna was installed at the Maimaga Observatory (MAM) of IKFIA, which is located $\sim 500 \mathrm{~km}$ southeast of ZGN. Gakona (GAK) is an observatory of Geophysical Institute, University of Alaska Fairbanks (GI-UAF). University of Florida and University of New Hampshire operate a loop antenna and an induction magnetometer, respectively, at Gakona. We installed an additional loop antenna and induction magnetometer at Gakona. Athabasca University Geophysical Observatory in Athabasca (ATH) is the oldest site among these stations. We installed an all-sky airglow/aurora imager and induction magnetometer there in 2005. The loop antenna and riometer were installed in 2012 and 2016, respectively. Kapuskasing (KAP) is a newly deployed station in 2016-2017 in collaboration with Virginia Tech. which operates a SuperDARN radar there. The PWING site is in a farmer's field about $10 \mathrm{~km}$ east of the radar site at KAP. Nain (NAI) is also a newly deployed station in 2017-2018 in collaboration with Augsburg College which operates a fluxgate magnetometer at NAI. The Husafell (HUS) site belongs to the National Institute of Polar Research (NIPR), Japan, which operates an induction magnetometer, a riometer, and a loop antenna. PWING deployed an all-sky airglow/ aurora imager at HUS. Kevo (KEV) is a site run by FMI where we installed an EMCCD camera in 2017.

As shown in Fig. 1, these eight stations (except for KEV) are distributed longitudinally around the north geomagnetic pole at $\sim 60^{\circ}$ MLAT with similar local time separation of $\sim 3 \mathrm{~h}$. This configuration is optimized to monitor longitudinal distribution of particles and waves in the inner magnetosphere around $L=4$. Some other preexisting sites shown by blue points shown in Fig. 1 help to see the latitudinal differences of the particles and waves.

Figure 2 shows photographs of the five types of instruments installed by the PWING project including their installation. The induction magnetometers (Fig. 2e, f), riometers (Fig. 2c), and loop antennas (Fig. 2g) are installed outside, while the all-sky imagers (Fig. 2a, b) and EMCCD cameras (Fig. 2j) are installed either in the container house or in the insulated camera box. All these five instruments are controlled by personal computers (PCs) in buildings (Fig. 2d). The four instruments except for EMCCD cameras are operated by Visual Basic software (Fig. 2h, i, k) developed by Institute for Space-Earth Environmental Research (ISEE), Nagoya University, for automated data acquisition. The EMCCD cameras are controlled by PCs with Linux OS.

\section{Description of the instruments and discussion All-sky airglow/aurora imager}

The all-sky airglow/aurora imagers developed for the PWING project have basically the same specifications as those used by the optical mesosphere thermosphere imagers (OMTIs) of the ISEE, Nagoya University (Shiokawa et al. 1999, 2009a). Thus these imagers are operated as part of the OMTIs network. Figure 3 shows the block diagram of the all-sky imager system. The optics of the imager is developed by KEO Scientific Ltd. (KEO Sentry 3) with a fish-eye lens (Mamiya 645 PRO, F4.0, $f=24 \mathrm{~mm}$ ) and a 6-position filter wheel. The cooled charge-coupled device (CCD) detector of the camera is made by Hamamatsu (C11090-22B) with $1024 \times 1024$ pixels. We use it with a $2 \times 2$ binning, and thus the image resolution is $512 \times 512$ pixels. The CCD camera and the filters are controlled by a Windows PC with software written in Visual Basic. The on/off time of the imager 
a

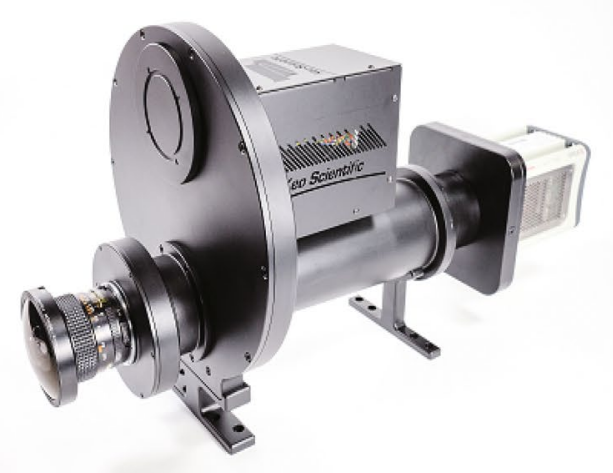

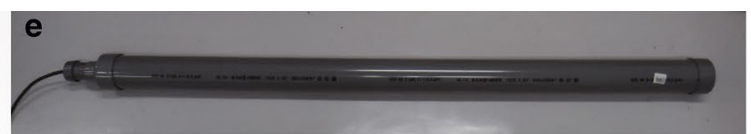

f

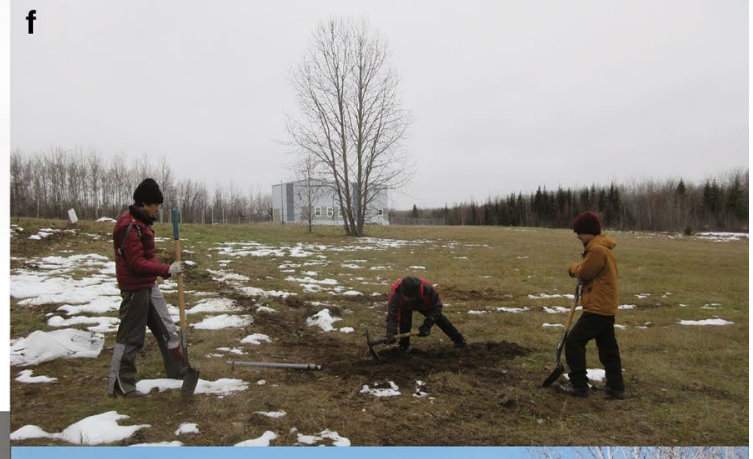

g

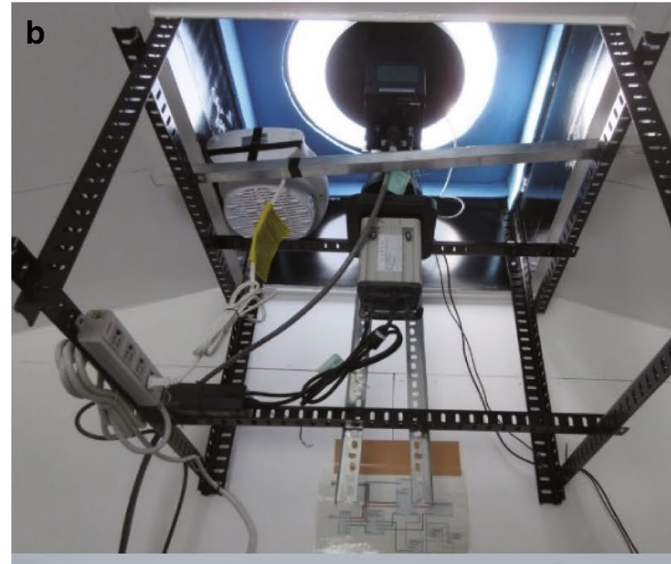

c
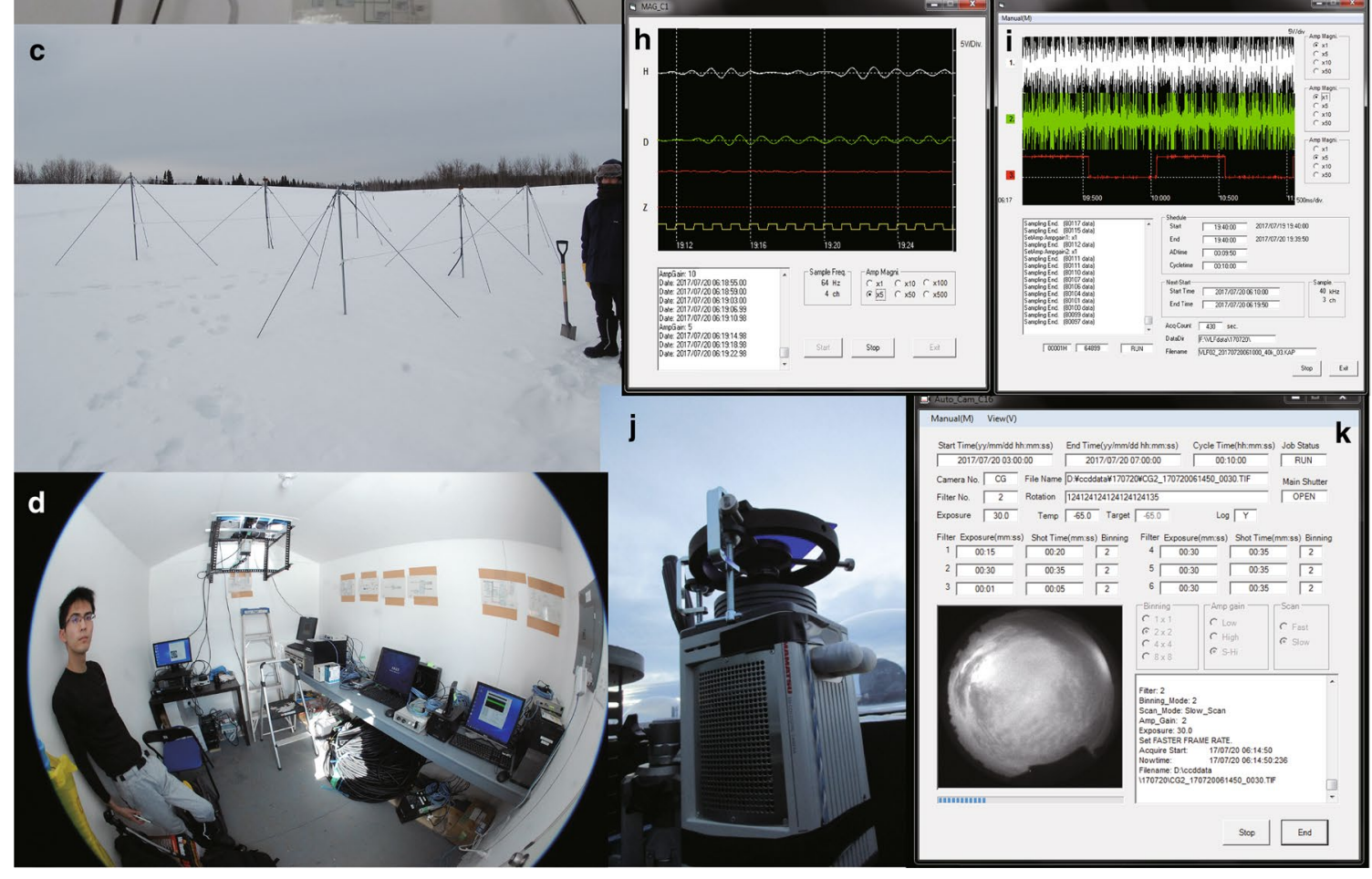

Fig. 2 Photographs of the five instruments installed by the PWING project for $\mathbf{a}, \mathbf{b}$ all-sky airglow/aurora camera at KAP, $\mathbf{c}$ riometer at KAP, $\mathbf{d}$ inside of container house at KAP, e, f induction magnetometer at ATH, $\mathbf{g}$ loop antenna at ATH, $\mathbf{h}$ PC window for magnetometer and riometer, $\mathbf{i}$ PC window for loop antenna, $\mathbf{j}$ EMCCD camera at ATH, and $\mathbf{k}$ PC window for all-sky airglow/aurora imager 


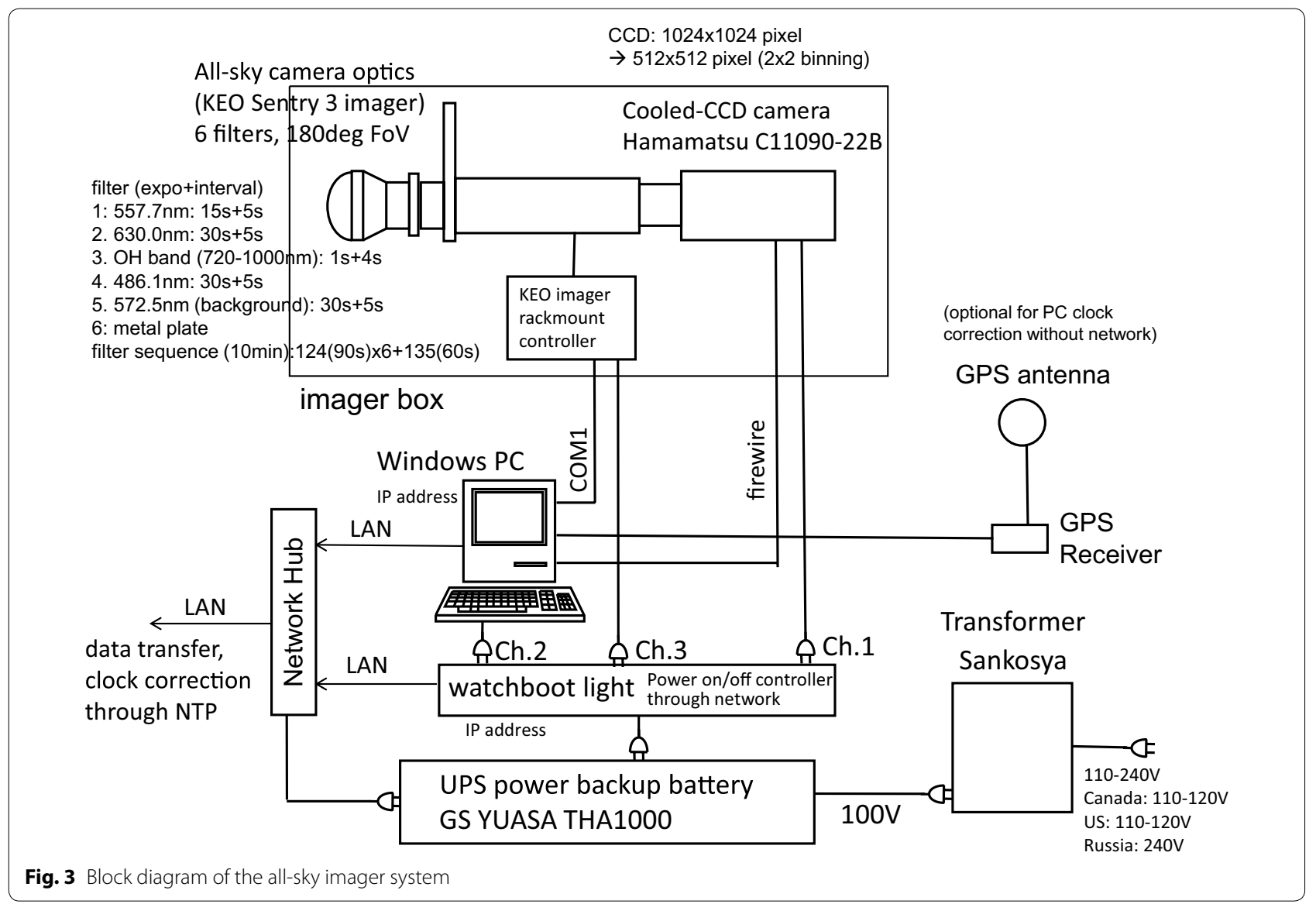

is pre-calculated by considering the condition that the elevation angles of the sun and moon are less than $-12^{\circ}$ and $0^{\circ}$ under the horizon, respectively, and written in a schedule file in the PC (filename: kansoku.txt). The filter sequence, exposure time of each filter, and binning are also set by another configuration file (filename: filter1. txt). Figure $2 \mathrm{k}$ shows the PC window of the imager control software in which these schedule and configuration parameters are shown. The CCD camera, optics, and PC can be restarted by the network power switch (watchboot) through the internet. The power of the whole system is backed up by an uninterruptible power supply (UPS). The transformer made by SANKOSHA with a power capacity of $1 \mathrm{kVA}$ is to convert local voltages to $100 \mathrm{~V}$ (Japanese standard) as well as to protect the system from surge currents on the power line (mainly due to lightning). The clock of the PC is synchronized to either the GPS clock or network time server to keep the correct time of data recording.

Table 2 shows the list of the interference filters used in the all-sky imagers and their specifications. As shown in the calibration dates, the imagers \#7 and \#14 were developed before the start of the PWING project (April 2016).
Imager \#7 has the optical system described by Shiokawa et al. (2009a), which is basically identical with that of the KEO Sentry 3 optics. Imager \#14 uses the KEO Sentry 3 optics. The other six imagers were developed by the PWING project after May 2016 and have basically identical specifications with the KEO Sentry 3 optics. All the PWING imagers have five filters to observe oxygen emissions at wavelengths of 557.7 and $630.0 \mathrm{~nm}$, hydroxyl $(\mathrm{OH})$ band emissions at $720-1000 \mathrm{~nm}$, hydrogen beta line at $486.1 \mathrm{~nm}$, and background continuum emissions without airglow/aurora lines at $572.5 \mathrm{~nm}$ at filter channels $1-5$, respectively. The sixth filter position is masked by a metal plate and used to reflect out the daylight when the observation is stopped. The bandwidths of these filters are 1.3-1.8 nm except for the $\mathrm{OH}$ band filters which pass emissions above $720 \mathrm{~nm}$. The CCD sensitivity is reduced at these longer wavelengths, becoming nearly zero at $\sim 1000 \mathrm{~nm}$. Usually one imager takes images of $557.7 \mathrm{~nm}$ (15-s exposure), $630.0 \mathrm{~nm}(30 \mathrm{~s})$, and $486.1 \mathrm{~nm}$ (30 s) every $1.5 \mathrm{~min}$. Thus time resolution of the all-sky imager for these three emissions is $1.5 \mathrm{~min}$. The images of $\mathrm{OH}$ band emissions ( $1 \mathrm{~s}$ ) and background emission at $572.5 \mathrm{~nm}(30 \mathrm{~s})$ are taken every $10 \mathrm{~min}$. 
Table 2 Filter characteristics, typical sensitivities, and exposure times of the all-sky imagers

\begin{tabular}{|c|c|c|c|c|c|c|}
\hline Filter number & Species & Observation wavelength $(\mathrm{nm})$ & Filter bandwidth (nm) & Typical sensitivity (count/r/s) & Exposure time (s) & Binning \\
\hline \multicolumn{7}{|c|}{ Camera \#7 (C7, Athabasca, calibration date: November 18, 2014, 512 × 512) } \\
\hline 1 & $\mathrm{Ol}$ & 557.7 & 1.760 & 0.2000 & 5 & $2 \times 2$ \\
\hline 2 & $\mathrm{Ol}$ & 630.0 & 1.650 & 0.3190 & 30 & $2 \times 2$ \\
\hline 3 & $\mathrm{OH}$ & $720-910$ & 190.000 & - & 1 & $2 \times 2$ \\
\hline 4 & $\mathrm{Hb}$ & 486.1 & 1.320 & 0.1930 & 40 & $2 \times 2$ \\
\hline 5 & $\mathrm{bg}$ & 572.5 & 1.630 & 0.2140 & 15 & $2 \times 2$ \\
\hline 6 & $\mathrm{Ol}$ & 844.6 & 1.200 & 0.1480 & 25 & $2 \times 2$ \\
\hline 7 & $\mathrm{Na}$ & 589.3 & 1.500 & 0.5430 & 15 & $2 \times 2$ \\
\hline \multicolumn{7}{|c|}{ Camera \#14 (CE, Zhigansk, calibration date: May 18, 2015, 512 × 512) } \\
\hline 1 & $\mathrm{Ol}$ & 557.7 & 1.636 & 0.2497 & 30 & $2 \times 2$ \\
\hline 2 & $\mathrm{Ol}$ & 630.0 & 1.645 & 0.3970 & 40 & $2 \times 2$ \\
\hline 3 & $\mathrm{OH}$ & $>720$ & - & - & 1 & $2 \times 2$ \\
\hline 4 & $\mathrm{Ol}$ & 865.0 & 9.837 & 0.1853 & 40 & $2 \times 2$ \\
\hline 5 & $\mathrm{bg}$ & 572.5 & 1.515 & 0.2935 & 30 & $2 \times 2$ \\
\hline \multicolumn{7}{|c|}{ Camera \#16 (CG, Kapuskasing, calibration date: December 26, 2016, 1024 × 1024) } \\
\hline 1 & $\mathrm{Ol}$ & 557.7 & 1.783 & 0.5185 & 15 & $2 \times 2$ \\
\hline 2 & $\mathrm{Ol}$ & 630.0 & 1.644 & 0.5343 & 30 & $2 \times 2$ \\
\hline 3 & $\mathrm{OH}$ & $>720$ & - & - & 1 & $2 \times 2$ \\
\hline 4 & $\mathrm{Hb}$ & 486.1 & 1.346 & 0.3558 & 30 & $2 \times 2$ \\
\hline 5 & $\mathrm{bg}$ & 572.5 & 1.498 & 0.4542 & 30 & $2 \times 2$ \\
\hline \multicolumn{7}{|c|}{ Camera \#17 (CH, Nain, calibration date: December 26, 2016, 1024 × 1024) } \\
\hline 1 & $\mathrm{Ol}$ & 557.7 & 1.757 & 0.4923 & 15 & $2 \times 2$ \\
\hline 2 & $\mathrm{Ol}$ & 630.0 & 1.677 & 0.5123 & 30 & $2 \times 2$ \\
\hline 3 & $\mathrm{OH}$ & $>720$ & - & - & 1 & $2 \times 2$ \\
\hline 4 & $\mathrm{Hb}$ & 486.1 & 1.373 & 0.3455 & 30 & $2 \times 2$ \\
\hline 5 & $\mathrm{bg}$ & 572.5 & 1.495 & 0.4567 & 30 & $2 \times 2$ \\
\hline \multicolumn{7}{|c|}{ Camera \#18 (Cl, Nyrola, calibration date: December 26, 2016, 1024 × 1024) } \\
\hline 1 & $\mathrm{Ol}$ & 557.7 & 1.742 & 0.5715 & 15 & $2 \times 2$ \\
\hline 2 & $\mathrm{Ol}$ & 630.0 & 1.632 & 0.6019 & 30 & $2 \times 2$ \\
\hline 3 & $\mathrm{OH}$ & $>720$ & - & - & 1 & $2 \times 2$ \\
\hline 4 & $\mathrm{Hb}$ & 486.1 & 1.375 & 0.4115 & 30 & $2 \times 2$ \\
\hline 5 & bg & 572.5 & 1.509 & 0.5472 & 30 & $2 \times 2$ \\
\hline \multicolumn{7}{|c|}{ Camera \#19 (CJ, Gakona, calibration date: December 26, 2016, 1024 × 1024) } \\
\hline 1 & $\mathrm{Ol}$ & 557.7 & 1.781 & 0.4966 & 15 & $2 \times 2$ \\
\hline 2 & $\mathrm{Ol}$ & 630.0 & 1.685 & 0.5504 & 30 & $2 \times 2$ \\
\hline 3 & $\mathrm{OH}$ & $>720$ & - & - & 1 & $2 \times 2$ \\
\hline 4 & $\mathrm{Hb}$ & 486.1 & 1.364 & 0.3621 & 30 & $2 \times 2$ \\
\hline 5 & bg & 572.5 & 1.492 & 0.4586 & 30 & $2 \times 2$ \\
\hline \multicolumn{7}{|c|}{ Camera \#20 (CK, Istok, calibration date: December 26, 2016, 1024 × 1024) } \\
\hline 1 & $\mathrm{Ol}$ & 557.7 & 1.717 & 0.5190 & 15 & $2 \times 2$ \\
\hline 2 & $\mathrm{Ol}$ & 630.0 & 1.627 & 0.6032 & 30 & $2 \times 2$ \\
\hline 3 & $\mathrm{OH}$ & $>720$ & - & - & 1 & $2 \times 2$ \\
\hline 4 & $\mathrm{Hb}$ & 486.1 & 1.344 & 0.4036 & 30 & $2 \times 2$ \\
\hline 5 & $\mathrm{bg}$ & 572.5 & 1.508 & 0.5242 & 30 & $2 \times 2$ \\
\hline \multicolumn{7}{|c|}{ Camera \#21 (CL, Husafell, calibration date: December 26, 2016, 1024 × 1024) } \\
\hline 1 & $\mathrm{Ol}$ & 557.7 & 1.769 & 0.4860 & 15 & $2 \times 2$ \\
\hline 2 & $\mathrm{Ol}$ & 630.0 & 1.614 & 0.5493 & 30 & $2 \times 2$ \\
\hline 3 & $\mathrm{OH}$ & $>720$ & - & - & 1 & $2 \times 2$ \\
\hline 4 & $\mathrm{Hb}$ & 486.1 & 1.379 & 0.3778 & 30 & $2 \times 2$ \\
\hline 5 & $\mathrm{bg}$ & 572.5 & 1.512 & 0.5030 & 30 & $2 \times 2$ \\
\hline
\end{tabular}


All these all-sky imagers were calibrated using facilities at NIPR, Japan, as has been done for other OMTIs imagers. Details of the calibration procedures were shown by Shiokawa et al. (2000). The sensitivities shown in Table 2 are mostly $0.2-0.6$ counts/R/s at the center of the images. The imagers developed by PWING (imagers \#16-21) have better sensitivities than those of previous OMTIs imagers (imagers \#7 and \#14 in Table 2 and those in Shiokawa et al. 1999, 2009a). This is mainly because of the increase of sensitivities of the CCD detectors. The sensitivity of 0.5 counts/R/s can give 600 counts for 10 $\mathrm{R}$ emissions with a $30 \mathrm{~s}$ exposure and a $2 \times 2$ binning $(=0.5 \times 10 \mathrm{R} \times 30 \mathrm{~s} \times 2 \times 2)$. The readout noise of the CCD camera is six electrons r.m.s. which is much smaller than the airglow counts. For Hamamatsu cooled CCD camera (C11090-22B), the 1 count corresponds to 1.26 electrons in the slow scan mode. The 600 counts with a signal-to-noise ratio $S / N=\frac{600}{\sqrt{600}}=24$ will be sufficient to study airglow/aurora structures in the images. Thus these imagers are highly sensitive to subvisual airglow/ auroral emissions.

Figure 4 shows the cross section of the sensitivities of the imagers \#16-21 with a filter \#1 for the $557.7 \mathrm{~nm}$ emission. The sensitivity decreases from the center to the edge of the images by about $20-30 \%$ because of decrease in transmission of the optics. This decrease in the sensitivity at an edge of the image is slightly larger than those shown by Shiokawa et al. (2000) for OMTIs imagers \#1-3. Since the front fish-eye lens (Mamiya 645 PRO) and the back imaging lens (Canon $50 \mathrm{~mm} / \mathrm{F} 0.95$ TV lens) are the same for all the OMTIs imagers, this difference would be due to the difference of the telecentric lenses in the middle of the optics. The small notches and dips

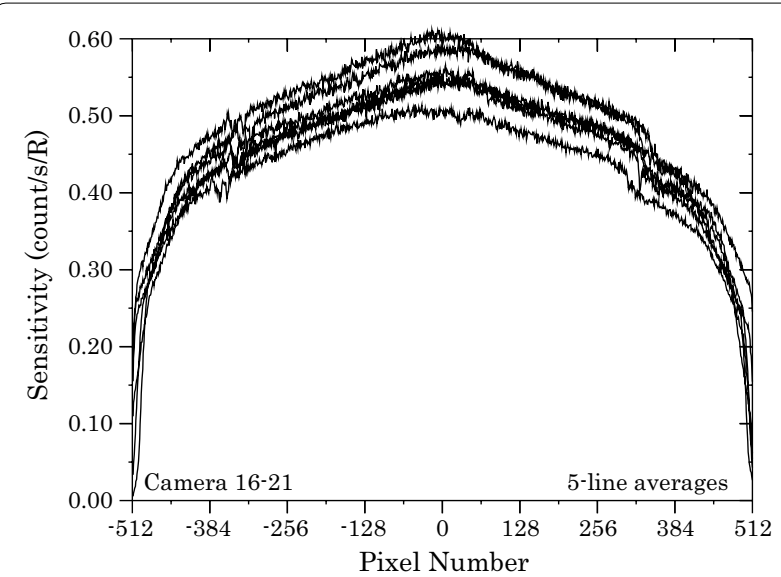

Fig. 4 Horizontal cross section of the sensitivities of the all-sky airglow/aurora imager \#16-21 measured by an integrating sphere of NIPR at $\sim \pm 350$ pixels are due to a defect (seam of two hemispheres) of the integrating sphere of the NIPR calibration facility.

Figure 5 shows examples of an auroral image and keograms for the $630.0 \mathrm{~nm}$ emission obtained by these allsky airglow/aurora imagers on March 30, 2017 during the 1st ERG-ground campaign observations. Five imagers at GAK, ATH, KAP, HUS, and NYR were in operation during the campaign. The keograms are the time sequence of meridional cross sections of the auroral images in geographic latitudes. The all-sky images are converted to geographical coordinates, assuming the height of auroras at $400 \mathrm{~km}$. This height assumption is higher than typical airglow and auroral altitudes. We adopted this assumption because stable auroral red (SAR) arcs [typical altitudes are $\sim 400 \mathrm{~km}$ (e.g., Rees and Roble 1975; Okano and Kim 1987)] were observed in the images. This night is during the recovery phase of the moderate geomagnetic storm that started on March 27, 2017.

In the keogram in Fig. 5a, auroral activity is seen in the northern sky of GAK after clouds disappear at 09:20 UT. A detachment of an arc from this northern aurora is observed at $\sim 12$ UT, indicating a detached SAR arc from the main auroral oval, as reported by Shiokawa et al. (2009b). A similar detachment of the SAR arc is seen at KAP in Fig. 5c at 03 UT. An image of this detached SAR arc is shown in Fig. 5f. This SAR arc is a very thin 630.0$\mathrm{nm}$ arc extended generally in the geomagnetically eastwest direction. The intensity is mostly less than $2 \mathrm{kR}$. The poleward part of the SAR arc below the main oval is filled by weaker $630.0 \mathrm{~nm}$ emissions with intensities less than $1 \mathrm{kR}$, suggesting that there is also precipitation of lowenergy electrons in this region. Because the SAR arc is a manifestation of interaction between ring-current highenergy ions with plasmaspheric low-energy electrons, the dynamical variation of SAR arcs provides useful information to monitor this interaction process from the ground. The sky at ATH was mostly clear on this night, but similar SAR arc was not observed at ATH, though ATH is at a longitude between GAK and KAP. This fact indicates longitudinal localization of the observed SAR arc. Active aurora was observed at HUS in Iceland throughout the plotted interval in Fig. 5d, while few activities are seen in NYR in Finland. This difference may be because HUS is at higher geomagnetic latitudes closer to the auroral zone. The combined observations of this night indicate the capability of the PWING all-sky imagers to observe the longitudinal structure of weak aurora/airglow phenomena.

\section{Induction magnetometer}

Several different types of induction magnetometer sensors are used in the PWING project. One is the 


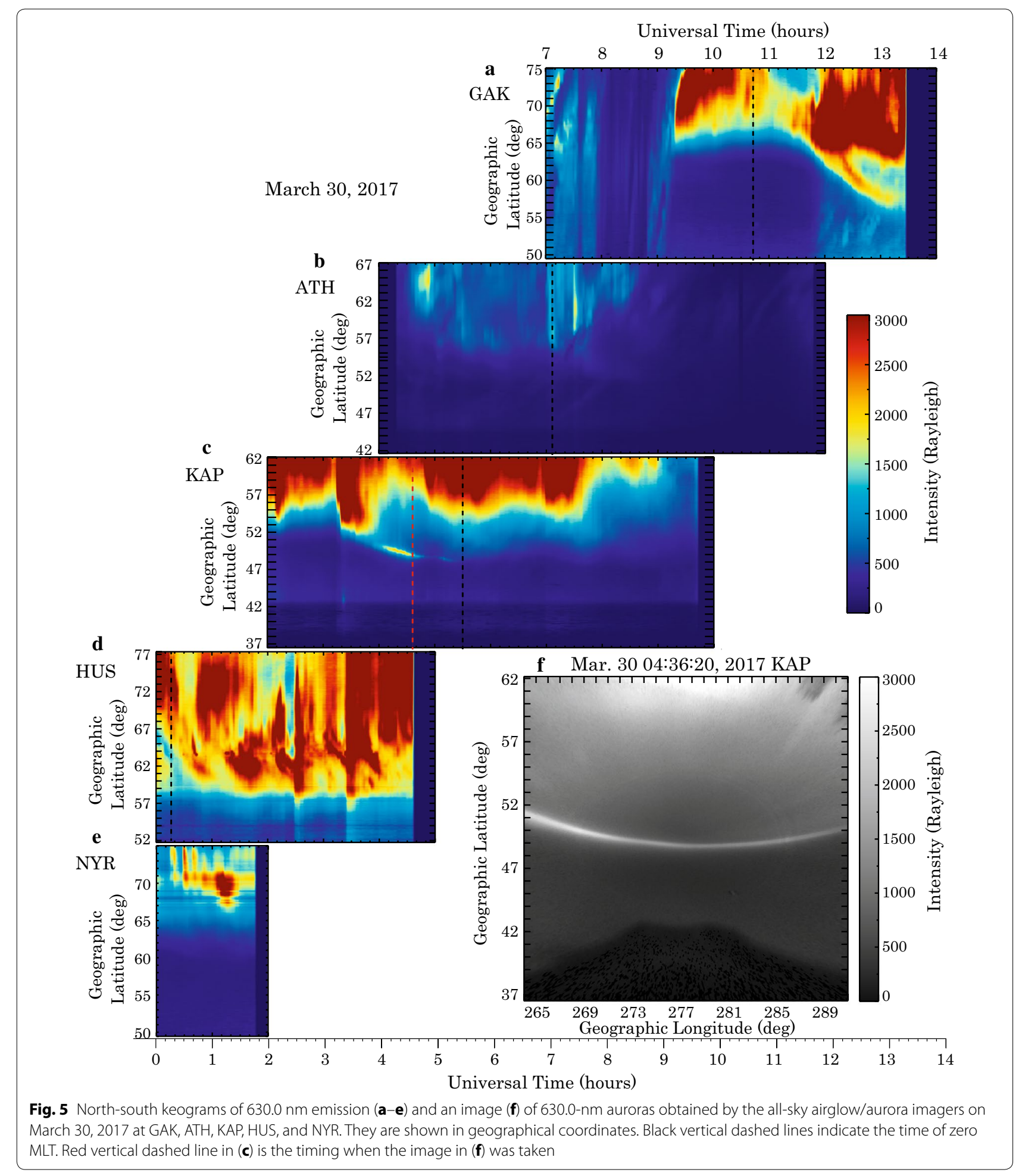

preexisting sensors before the PWING project, i.e., those made by Tierra Technica (ULC-150) for ZGN and those reused from the STEP polar magnetometer network in Canada for ATH. The amplifiers of these sensors were assembled by ISEE, Nagoya University, and details are given by Shiokawa et al. (2010). New sensors (Schlumberger BF-10 sensors with an amplifier by Tohoku Denshi Sangyo) were also introduced for the PWING project by 
the National Institute of Information and Communications Technology (NICT) for KAP, GAK, and NAI. The induction magnetometers at the SGO stations and at IST by ISTP are made by the Laboratory of Electromagnetic Innovations (LEMI) in Ukraine. The induction magnetometer at HUS has been run by NIPR since 1983.

Figure 6 shows the block diagram of the induction magnetometer and riometer system developed for the PWING project. The induction magnetometer sensors are buried under the ground as shown in Fig. 2f. We put the sensors into insulated PVC pipes to avoid penetration of water into the sensor. The sensors are usually $\sim 200 \mathrm{~m}$ away from the main building to avoid electromagnetic noise from the power. The recording is made by a Windows PC with a software written in Visual Basic to control the analogue-to-digital (A/D) conversion board. The sampling rate is $64 \mathrm{~Hz}$. Geomagnetically northward (H-) component and eastward (D-) component are recorded in the first and second channels, respectively, while the riometer output is recorded at the third channel. The 1 pulse-per-second (PPS) signal generated by a GPS receiver is recorded in the fourth channel as a time standard. The PC window of the data recording software is shown in Fig. $2 \mathrm{~h}$, in which the output curves of channel 1-4 are shown from top to bottom in white, green, red, and yellow curves. The PC clock is synchronized to standard time either by the GPS receiver via serial cable or by the network time server. The watchboot, UPS, and power transformer have the same specifications as those used for the all-sky imager.

Figures 7 and 8 show the sensitivities and phases of the induction magnetometers of BF-10 (amp001, amp002, and amp003 for KAP, GAK, and NAI, respectively) and ULC-150 for ZGN. The six BF-10 sensors show almost identical sensitivities and phases. The three ULC-150 sensors also show nearly identical sensitivities and phases. The sensitivities of the BF-10 sensors are nearly flat at $0.4-0.6 \mathrm{~V} / \mathrm{nT}$ at frequencies from 0.3 to $10 \mathrm{~Hz}$. On the other hand, the sensitivity of the ULC-150 sensors for ZGN linearly increases with frequencies up to the peak of $0.38 \mathrm{~V} / \mathrm{nT}$ at $1.4 \mathrm{~Hz}$, as expected from the ordinary coil response to the input magnetic field variations, and then decreases toward higher frequencies due to low-pass filters. These sensitivity and phase responses of ULC-150 are similar to those of other ULC-150 magnetometers used at Magadan and Paratunka, Russia (Shiokawa et al. 2010).

As shown in Table 1, installation of the induction magnetometers had been finished for seven stations by the time of the first ERG-ground campaign in March 2017. Figure 9 shows an example of the dynamic spectra of magnetic field variations at $0.1-32 \mathrm{~Hz}$ observed by these

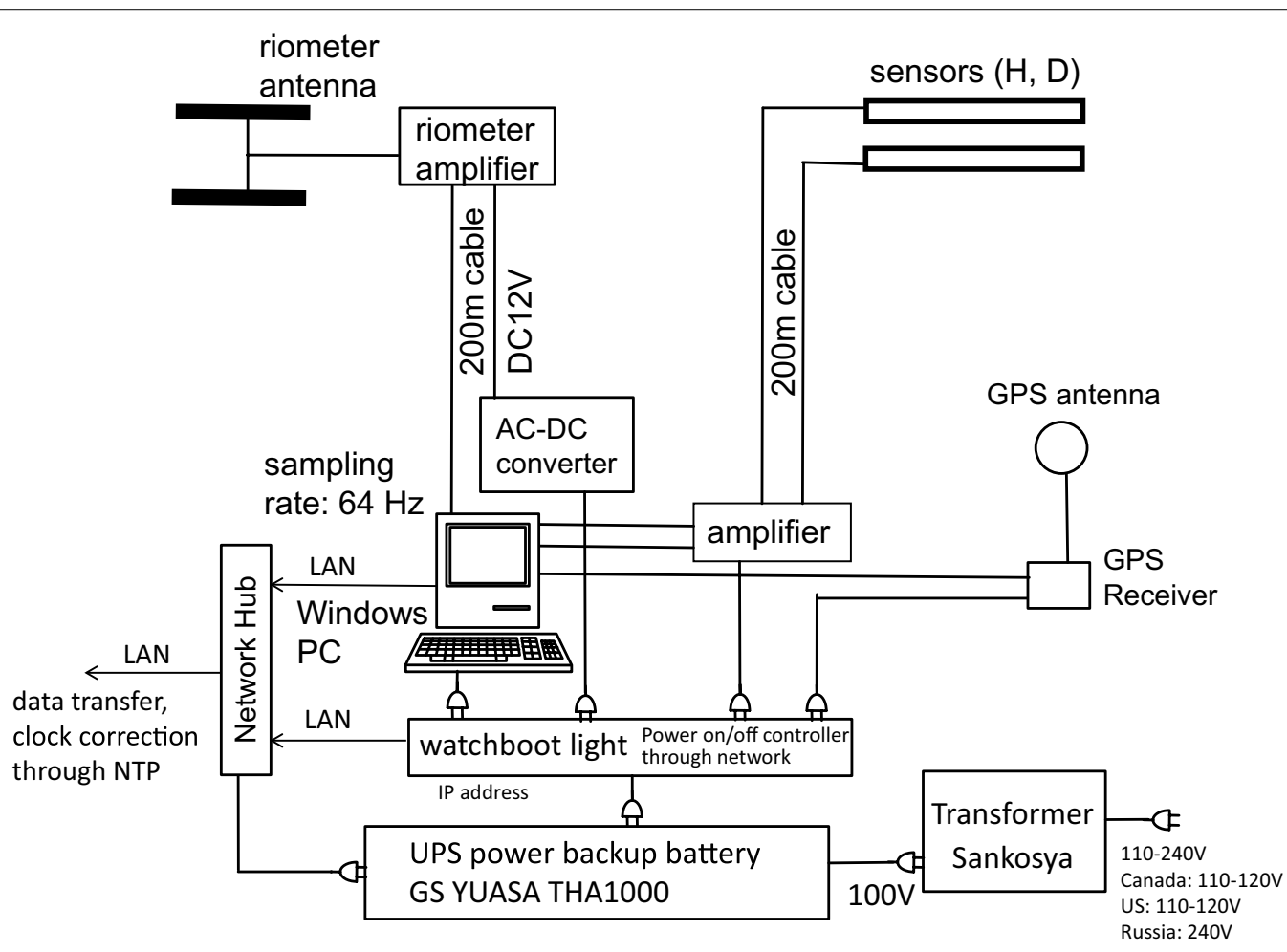

Fig. 6 Block diagram of the induction magnetometer and riometer system 


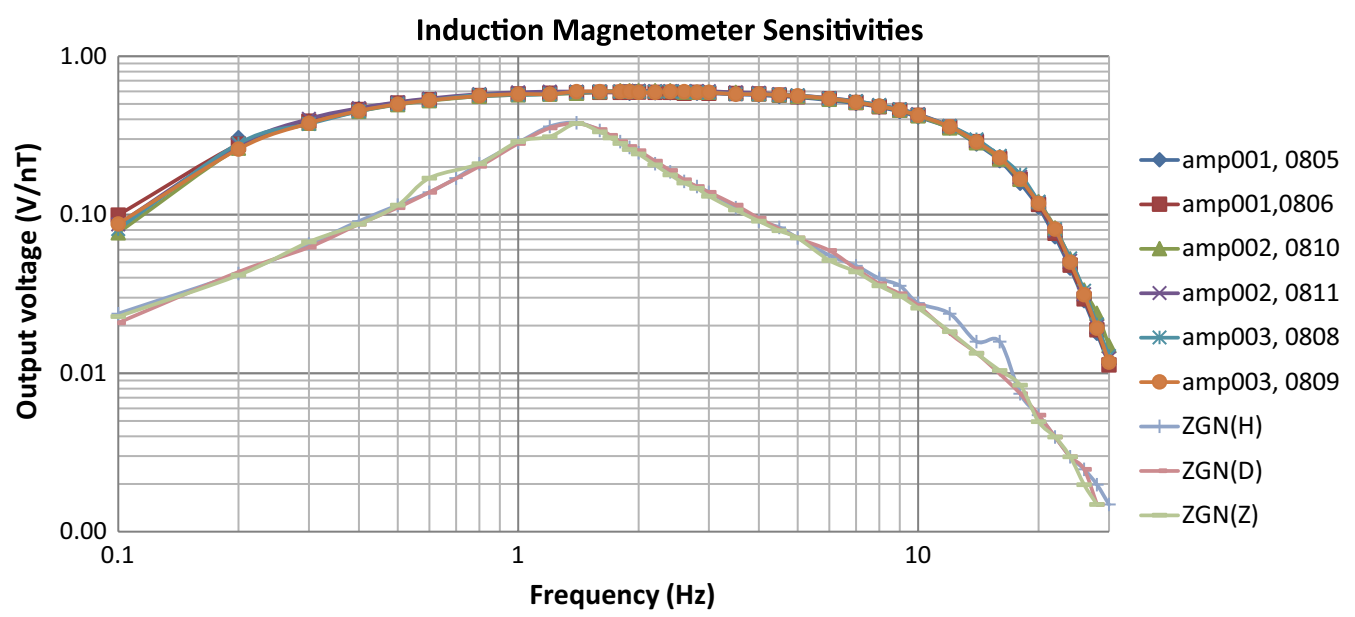

Fig. 7 Frequency dependence of sensitivities of the induction magnetometers

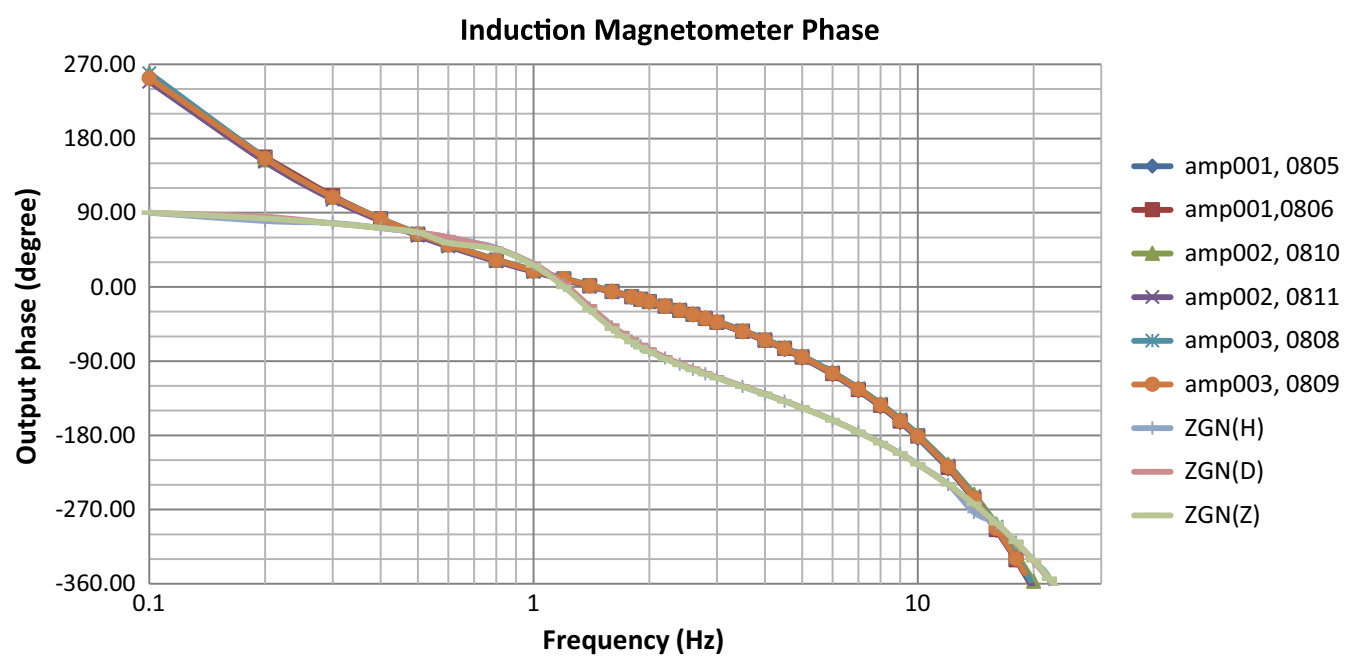

Fig. 8 Frequency dependence of phase of the induction magnetometers

induction magnetometers at seven stations on March 30, 2017, during the campaign period. The broadband bursty emissions are Pi burst (PiB). For example, two PiBs are nearly simultaneously observed at $15 \mathrm{UT}$ and $17 \mathrm{UT}$ at IST and ZGN (Fig. 9b, c), while such PiB is not clear at neighboring stations at NUR in Finland (Fig. 9a) and at ATH (Fig. 9e). This reflects the local time extent of less than $7 \mathrm{~h}$ of the ionospheric and field-aligned current perturbations that create the observed $\mathrm{PiB}$ variations around the midnight associated with substorm auroras. Monochromatic emissions at a frequency range of $\sim 1 \mathrm{~Hz}$ were observed at GAK, ATH, and KAP (Fig. 9d-f) at 07-12 UT in the midnight-post-midnight local times, indicating the local time extent of $\sim 5.5 \mathrm{~h}$. They are Pc1 magnetic pulsations, which correspond to EMIC waves in the magnetosphere. Simultaneously, Pc1 pulsations with lower frequencies at $0.2-0.3 \mathrm{~Hz}$ are observed at NUR, IST, and ZGN (Fig. 9a, c) in the noon-dusk sector. The monochromatic emission observed only at NUR at $\sim 18$ UT with increasing frequencies seems to be the intervals of pulsations diminishing in periods (IPDP). Unfortunately, the data at HUS are rather noisy particularly at lower frequencies, and the noises prevent us to identify corresponding wave activities.

The observations shown in Fig. 9 indicate the capability of the PWING induction magnetometers to monitor the longitudinal extent of the PiB and Pc1/EMIC magnetic pulsations. Engebretson et al. (2015) recently reported intense EMIC waves extending over 12-h MLTs using combined ground and satellite measurements. The 


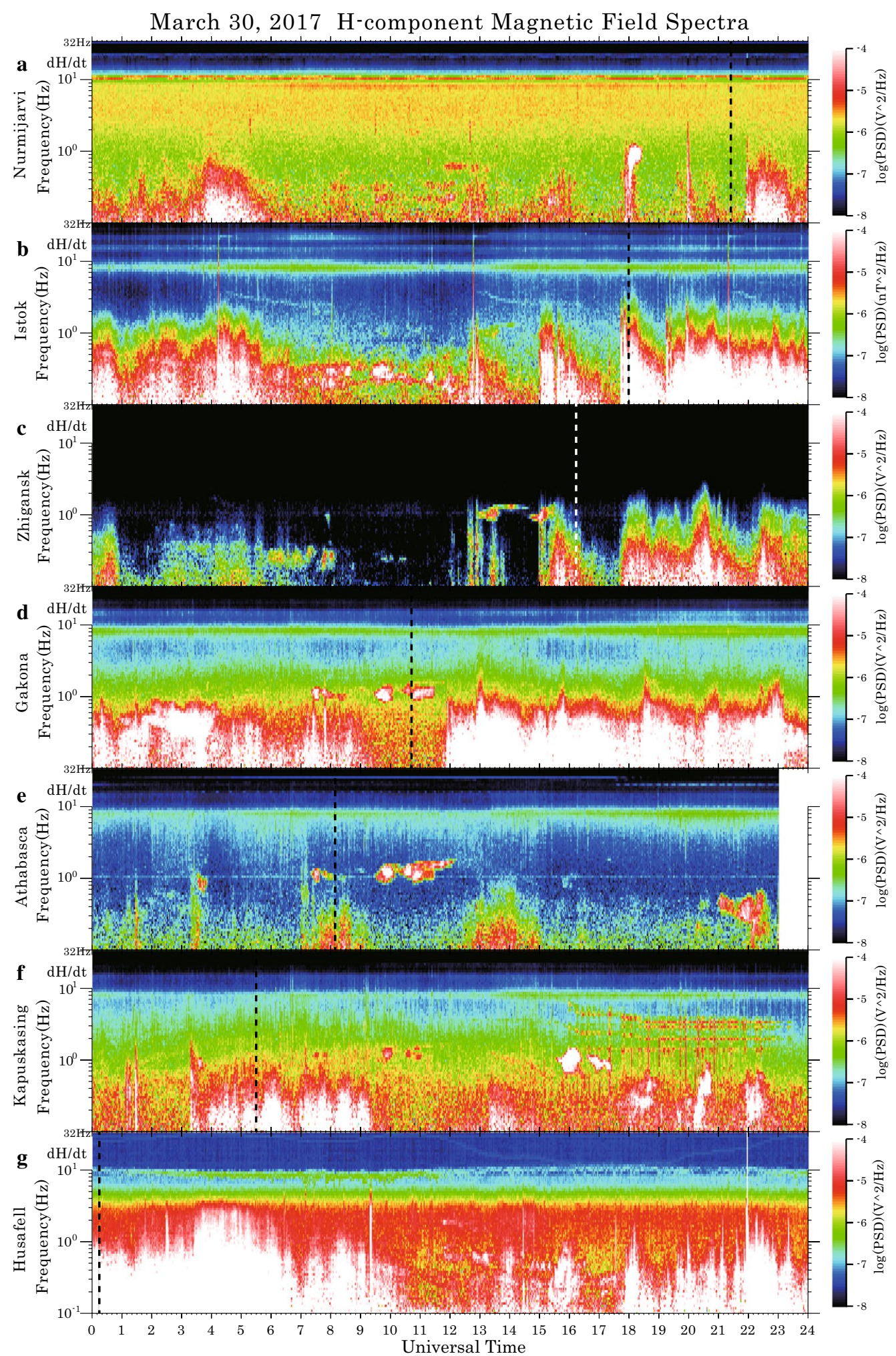

Fig. 9 One-day dynamic spectra of $\mathrm{H}$-component magnetic field variations observed at seven stations around the north geomagnetic pole on March 30, 2017. Vertical dashed lines indicate 00 MLT (magnetic local midnight) at each station 
PWING magnetometers can provide the opportunity to monitor the spatial extent of such waves on a routine basis. The Pc1 waves propagate horizontally through the ionospheric duct over a few thousand kilometers (e.g., Fraser 1975; Kawamura et al. 1981). As shown by Jun et al. $(2014,2016)$, comparison of Pc1 pearl structures (amplitude modulation) at different stations may help understanding the generation mechanisms of the pearl structure through beating of different waves during duct propagation. Comparison with all-sky airglow/aurora imager data gives us an interesting opportunity to monitor interaction between EMIC waves and ring-current protons/relativistic electrons (e.g., Sakaguchi et al. 2007, 2008, 2012; Miyoshi et al. 2008; Nomura et al. 2011, 2012, 2016; Ozaki et al. 2016).

\section{Broad-beam riometer}

The broad-beam riometer is made by La Jolla Sciences with an operating frequency of $30 \mathrm{MHz}$ and a frequency bandwidth of $250 \mathrm{kHz}$. The riometer has dual half-wave dipole antennas with a separation of 14 feet $(4.27 \mathrm{~m})$ at more than 60 inches $(1.52 \mathrm{~m})$ above the ground (Fig. 2c). Two reflectors are located 30 inches $(0.76 \mathrm{~m})$ below the antennas. As shown in Fig. 6, the intensities of $30 \mathrm{MHz}$ radio waves from the galaxy and active radio stars are amplified by the riometer receiver near the antenna, transferred to the main building with a 200-m signal cable, and recorded at the third channel of the recording PC with a sampling rate of $64 \mathrm{~Hz}$. The recording PC is the same as that used for recording of the induction magnetometer data.

Figure 10 shows an example of the broad-beam riometer data obtained at GAK, ATH, KAP, and HUS on March 30, 2017, during the first ERG-ground campaign period. The output voltages, which are proportional to the $30-\mathrm{MHz}$ radio wave intensity, are plotted in Fig. 10b, d, f, h. The quiet-day curves (QDCs) are also shown by thin curves in these panels. The QDCs are calculated every $1 \mathrm{~s}$ as the 70th percentile of the 1984 $(=64 \mathrm{~Hz} \times 31$ days $)$ data points of the riometer output voltages (Vout) for \pm 15 days of the observation day. By using the QDC, we calculate cosmic noise absorption (CNA) as $10 \log 10$ (QDC/Vout).

In Fig. 10, strong CNA of more than $2 \mathrm{~dB}$ is observed at GAK and ATH after 11 UT in the second half of the day in the post-midnight to noon local time sectors. The CNA is caused by absorption of $30-\mathrm{MHz}$ radio waves in the D-region ionosphere at altitudes of $60-90 \mathrm{~km}$ associated with high-energy $(\sim 30-100 \mathrm{keV})$ electron precipitation. Thus the CNA enhancement in the post-midnight to noon local times is consistent with the downward drift and energization of electrons in the inner magnetosphere. These data are useful to monitor the longitudinal

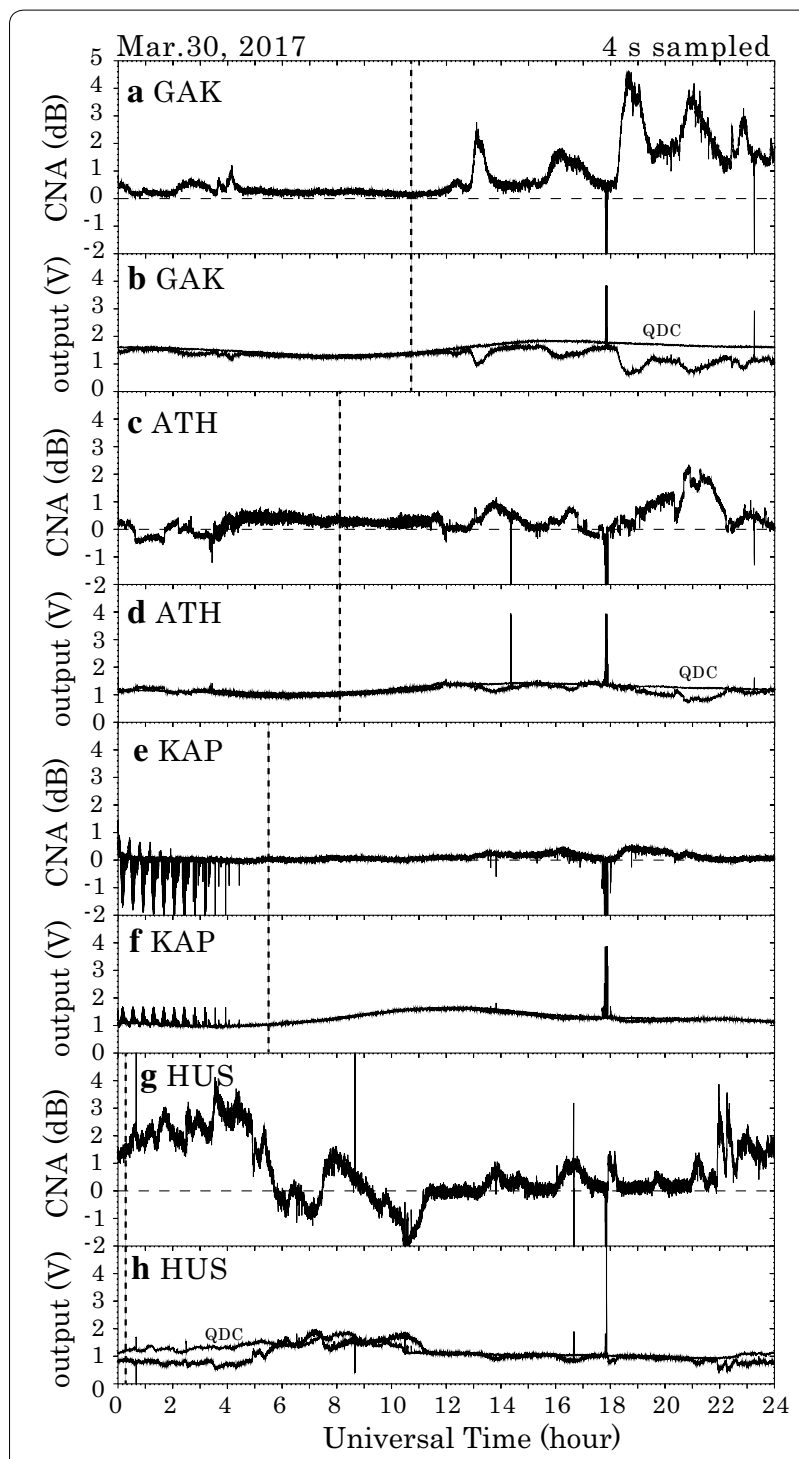

Fig. 10 Output voltages, quiet-day curves (QDCs) and cosmic noise absorption (CNA) measured by the broad-beam riometer at GAK, ATH, KAP, and HUS on March 30, 2017. Vertical dashed lines indicate the time of zero MLT (magnetic midnight) at each station

extent of high-energy electron precipitation at subauroral latitudes. GAK and HUS observe stronger CNA than those at ATH and KAP. This may be because GAK and HUS are at slightly higher latitudes closer to the auroral zone. The data before $04 \mathrm{UT}$ at KAP are contaminated by local radio noise.

In the PWING project, the effects of ionization change in the lower ionosphere due to energetic electron precipitation $(>100 \mathrm{keV})$ are also measured by using VLF/LF radio wave receivers along the propagation path between standard VLF/LF transmitters and the receivers (Adachi et al. 2009). Vertical monopole antennas for this purpose 
were installed at ATH on October 24, 2010, (before PWING) and MAM on April 21, 2017.

\section{Loop antenna}

The loop antennas developed by the PWING project for the ELF/VLF wave measurements are made by the Creative Design Corp. (HR130C) with pre-amplifiers made by the Meiwa System (VLF-lL2). They are basically the same as those used by Ozaki et al. (2012) at the Syowa Station in Antarctica. The antenna at Kannuslehto (KAN, $67.7^{\circ} \mathrm{N}$, $26.3^{\circ} \mathrm{E}$ ), operated by $\mathrm{SGO}$ is different from these PWING antennas, and is a $10 \mathrm{~m}$ by $10 \mathrm{~m}$ square loop antenna in north-south and east-west directions with 10 turns each, as described in detail by Manninen (2005).

Figure 11 shows the block diagram of the loop antenna system. The delta-type loop antenna (HR-130C) has a $5.3 \mathrm{~m}$ height and $\mathrm{a} \sim 15 \mathrm{~m}$ width including the antenna stay wire in geomagnetically north-south and east-west directions, as shown in Fig. 2g. The antenna has a 10-turn loop for each direction. The antenna and pre-amplifier are $\sim 300 \mathrm{~m}$ away from the main building to avoid electromagnetic noise from the power line. The recording is made by a Windows PC with software written in Visual Basic to control the analogue-to-digital (A/D) conversion board. The sampling rate is $40 \mathrm{kHz}$. Magnetic field variations in geomagnetically northward and eastward directions are recorded in the first and second channels, respectively, while the 1 PPS signal generated by a GPS receiver is recorded in the third channel as a time standard. The PC window of the data recording software is shown in Fig. 2i, in which the output curves of channel 1-3 are shown from top to bottom in white, green, and red curves. The recording is made for $590 \mathrm{~s} \mathrm{(9} \mathrm{min} 50 \mathrm{~s}$ ) every $10 \mathrm{~min}$, allowing 10 -s resting time for the $\mathrm{PC}$ to avoid memory hang up. The PC clock is synchronized to the standard time either by the GPS receiver via a serial cable or by the network time server. The watchboot, UPS, and power transformer are the same as those used for the all-sky imager, induction magnetometer, and riometer.

Because of the high-sampling rate of $40 \mathrm{kHz}$, the data size of the loop antenna becomes huge $(0.7 \mathrm{~TB}$ per month). To store these huge data, an extra hard disk of $\sim 10 \mathrm{~TB}$ was attached in the PC. Because of this huge data size, calculation of the dynamic spectra also takes time. We install an additional Linux PC, which shares the hard disk, to calculate dynamic spectra of the ELF/VLF waves every $10 \mathrm{~min}$ in near real time, and store both the raw waveform data and the spectral data into the hard disk. The size of the spectral data is much smaller (25 GB per month) than the original data. This on-site data processing and data-size reduction is essentially important to monitor the operation of the system remotely from Japan, since we cannot transfer the raw data via the network. The raw data are copied into a 2-TB portable hard disk every 2 months which is mailed to Japan via post by local collaborators.

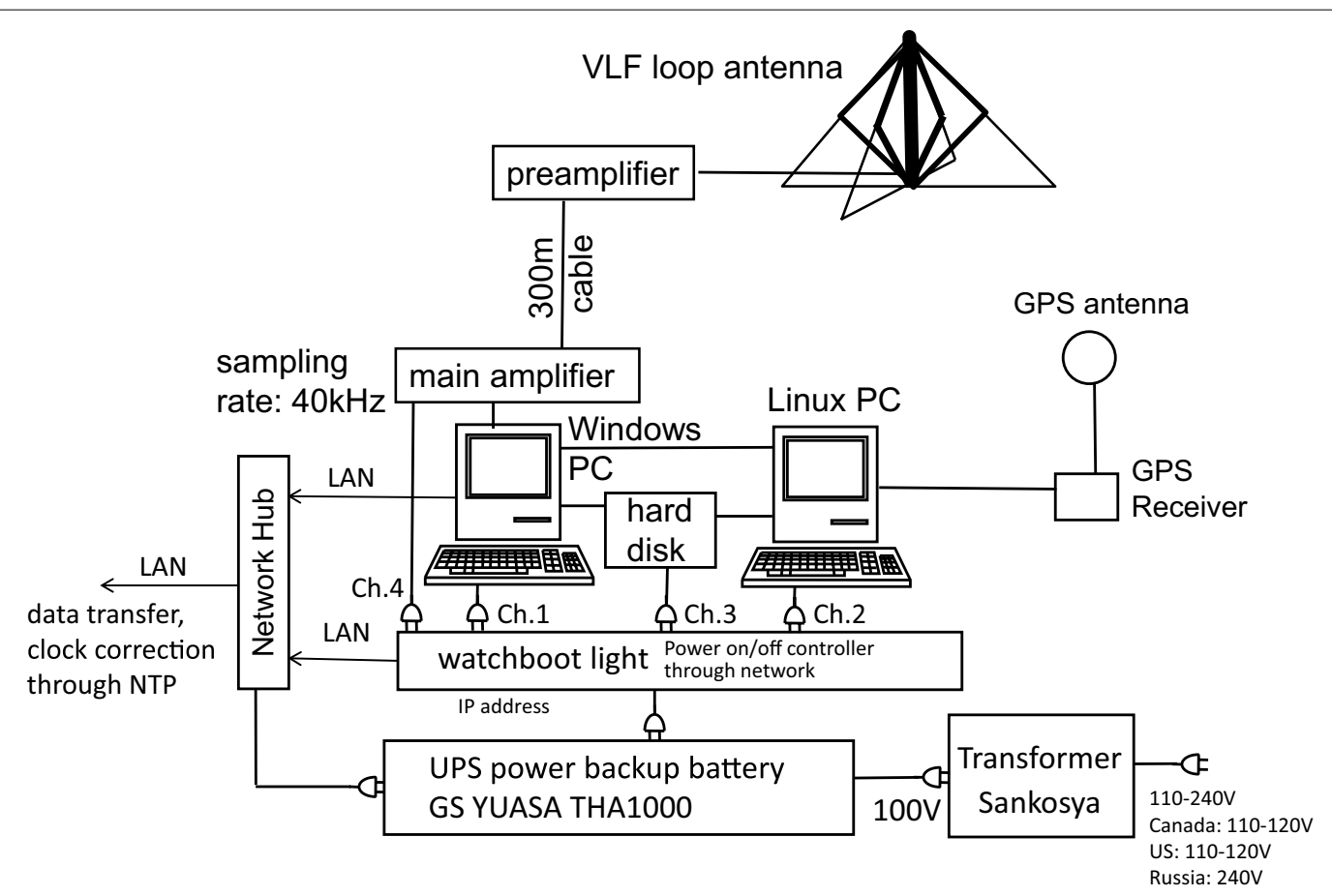

Fig. 11 Block diagram of the loop antenna system for ELF/VLF wave measurements 


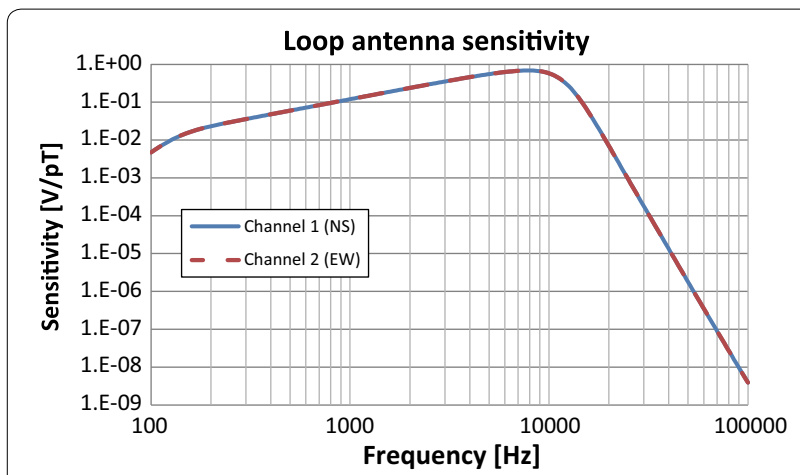

Fig. 12 Frequency dependence of sensitivities of the loop antenna to measure the ELFNLF radio waves

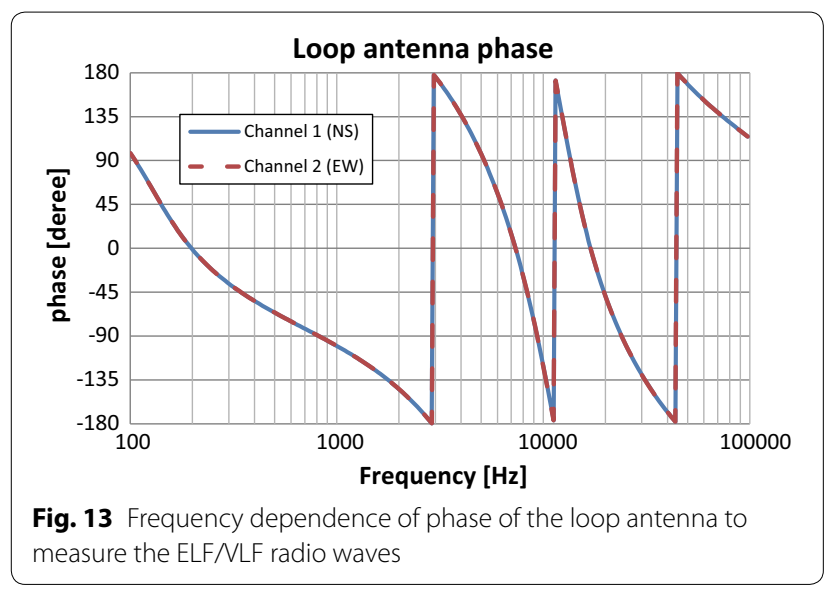

Figures 12 and 13 show frequency dependence of sensitivities and phase of the loop antennas used at ATH. The highest sensitivity is $0.69 \mathrm{~V} / \mathrm{pT}$ at $8 \mathrm{kHz}$. The sensitivity linearly increases at $0.2-8 \mathrm{kHz}$, as expected from loop response to the magnetic field variations, and then decreases rapidly at above $10 \mathrm{kHz}$ due to low-pass filter. The loop antenna sensitivity is more than $0.01 \mathrm{~V} /$ pT at $0.13-20 \mathrm{kHz}$. The phase relationship between the input radio signal and output voltage signal rotates two times in this frequency range. These sensitivity and phase curves are nearly identical for the channels 1 and 2 .

The sensitivity and phase curves of the loop antenna for ATH in Figs. 12 and 13 were measured for the maximum gain volume of the pre-amplifier and $20 \mathrm{~dB}$ gain (defined as no attenuation) for the volume of the main amplifier. The gain volume of the pre-amplifier is always set to be maximum at all the PWING stations, while the gain volume (attenuator) of the main amplifier is adjusted depending on the noise level of the stations.

Figure 14 shows an example of the 1-day dynamic spectra of the ELF/VLF waves observed at KAN, ATH, and KAP on March 30, 2017, during the 1st ERG-ground campaign. Vertical dashed lines in each panel indicate the location of magnetic midnight. The contamination from global lightning activities is seen at frequencies above $\sim 4 \mathrm{kHz}$ at all the stations at night because of less attenuation of the radio waves from lightning through the ground-ionosphere waveguide at night. The ELF/VLF waves originating from the magnetosphere can be seen at frequencies below $4 \mathrm{kHz}$ at KAN intermittently at $01-12$, 13-17, and 22-23 UT, and at ATH at 15-20 UT. On the other hand, no magnetospheric ELF/VLF activities are recognized at KAP, though KAP is only $2.6 \mathrm{~h}$ different from ATH in MLT. Strong line emissions are observed at KAP at frequencies below $\sim 4 \mathrm{kHz}$ at 13-21 UT due to human activities in daytime.

The intensity color scale of KAP is two orders larger than that of ATH. Considering this color scale, the intensity of lightening at $09-11$ UT at KAP is about 1.5 order stronger than that at ATH. In the conversion from the raw voltage data to this absolute intensity, we used the sensitivity curve shown in Fig. 12. Since the gain volume of the main amplifier at ATH and KAP is $20 \mathrm{~dB}(0 \mathrm{~dB}$ attenuation) and $6 \mathrm{~dB}$ (14 dB attenuation), we reduced the sensitivity at KAP to be $14 \mathrm{~dB}$ smaller than that at ATH in Fig. 12. However, this procedure may cause some ambiguity of the absolute gain due to the ambiguity of the gain of the main amplifier. We are planning to do onsite calibration of the VLF antenna to fix this ambiguity at KAP.

Figure 15 shows 10-min dynamic spectra observed at ATH and KAP at 1800-1810 UT on March 30, 2017. These plots are shown with the power of the original output voltages $\left(\mathrm{V}^{2} / \mathrm{Hz}\right)$ to avoid saturation at the lower frequency side. Quasi-periodic chorus emissions at frequencies below $3 \mathrm{kHz}$ are seen at ATH at 1800-1803 UT and change their spectral shape to more hiss-like at after 1803 UT. On the other hand, no such chorus/hiss emissions are seen at KAP.

The comparison of KAN, ATH, and KAP indicates the capability of the PWING loop antennas to monitor the spatial extent of the magnetospheric ELF/VLF waves at subauroral latitudes. Although the chorus emissions were observed at ATH over $5 \mathrm{~h}$ at $15-20 \mathrm{UT}$, no emission was observed at KAP at 2.6-h different MLT. This indicates that the magnetospheric ELF/VLF emissions can be generated in a quite localized region. These emissions are considered to be generated by temperature anisotropy of drifting high-energy electrons in the inner magnetosphere (e.g., Kennel and Petschek 1966). Such high-energy $(\sim 10-100 \mathrm{keV})$ electrons drift around the Earth with a time scale of several hours. Thus it seems to be difficult to create a localized distribution of drifting electrons with scale sizes less than $2.6 \mathrm{~h}$ in MLT. The background plasma density also controls the generation 


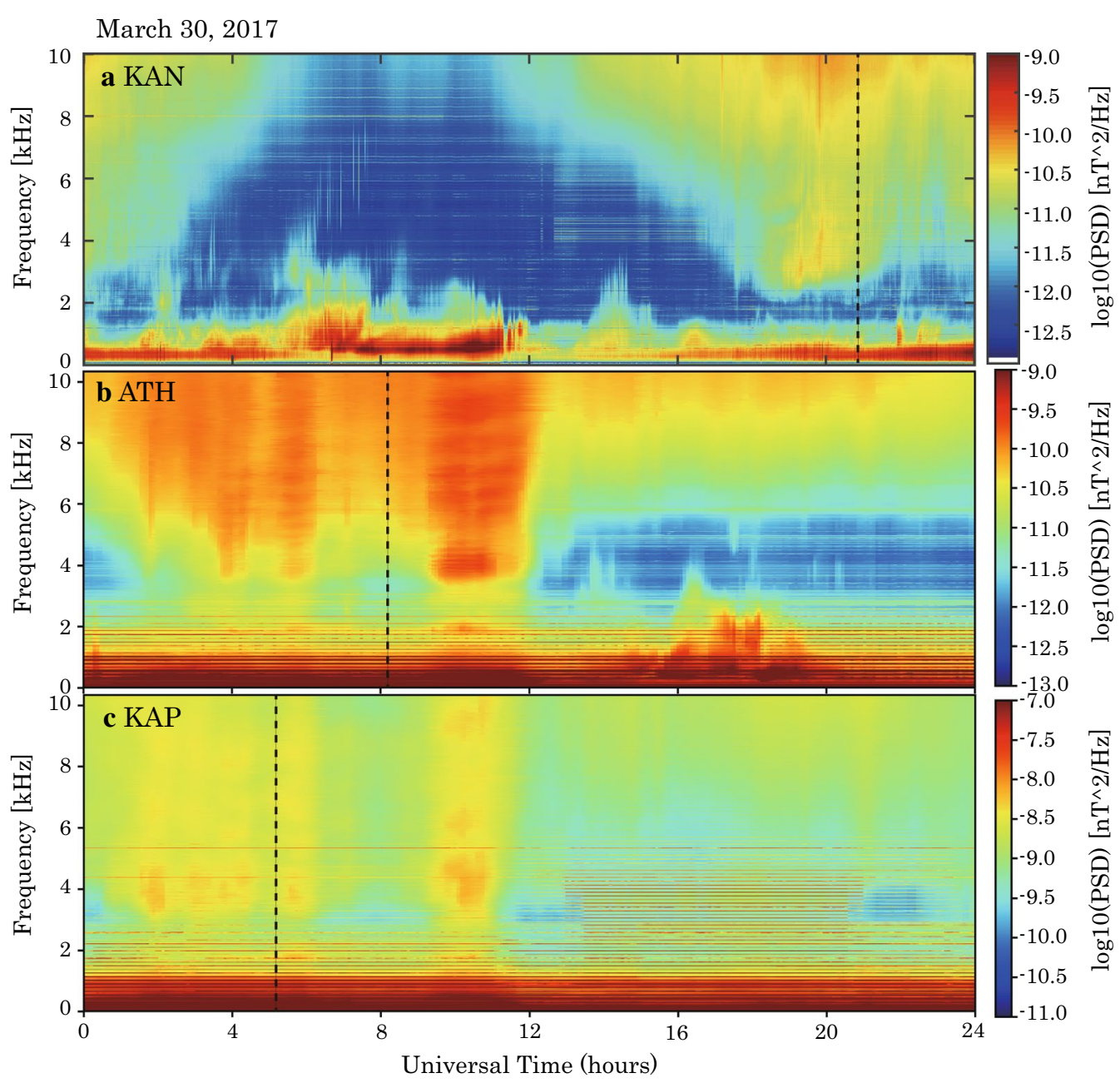

Fig. 14 Twenty-four-hour spectra of ELFNLF waves (north-south magnetic field variations) observed by loop antennas at KAN, ATH, and KAP. Vertical dashed lines indicate the time of zero MLT (magnetic midnight) at each station

and propagation of the magnetospheric ELF/VLF waves and may cause the observed localization of the magnetospheric ELF/VLF waves. As shown by Ozaki et al. (2008), the ELF/VLF waves expand only about $500 \mathrm{~km}$ from the exit point of the ionosphere to the ground, allowing the PWING stations to see the localization of the magnetospheric ELF/VLF waves.

Recently Yonezu et al. (2017) examined the simultaneous occurrence rate of the magnetospheric ELF/VLF emissions using 48-day loop antenna data obtained at ATH, KAN, and the Syowa station in Antarctica. These stations are separated in local times of 3,8 , and $11 \mathrm{~h}$. The simultaneous occurrence rates are $9.8,2.5$, and $3.6 \%$ for SYO-KAN (3-h local time difference), ATH-SYO (8 h), and ATH-KAN (11 h), respectively. However, this analysis does not consider the difference of spectral features (structures and frequencies) of the waves, because the data are obtained with loop antennas of different specifications and sampling rates. In the PWING project, we expect to use quite a uniform dataset for comparison of the waves at different local times. Comparison with Arase and Van Allen Probes also provides important information on the propagation of magnetospheric ELF/VLF waves to the ground (e.g., Martinez-Calderon et al. 2016).

\section{EMCCD camera}

The EMCCD cameras used by the PWING project are made by Hamamatsu (C9100-23B) with a fish-eye lens (Fujinon FE185C086-1, F1.8). It has nearly an all-sky field of view. Broadband filters, named as BG3 for transmission wavelengths at $300-500 \mathrm{~nm}$ and above $700 \mathrm{~nm}$ or named as RG665 for wavelengths above $665 \mathrm{~nm}$, are set on top of the fish-eye lens, as shown in Fig. 2j. They remove both the 557.7 and the $630.0 \mathrm{~nm}$ emissions, yet 


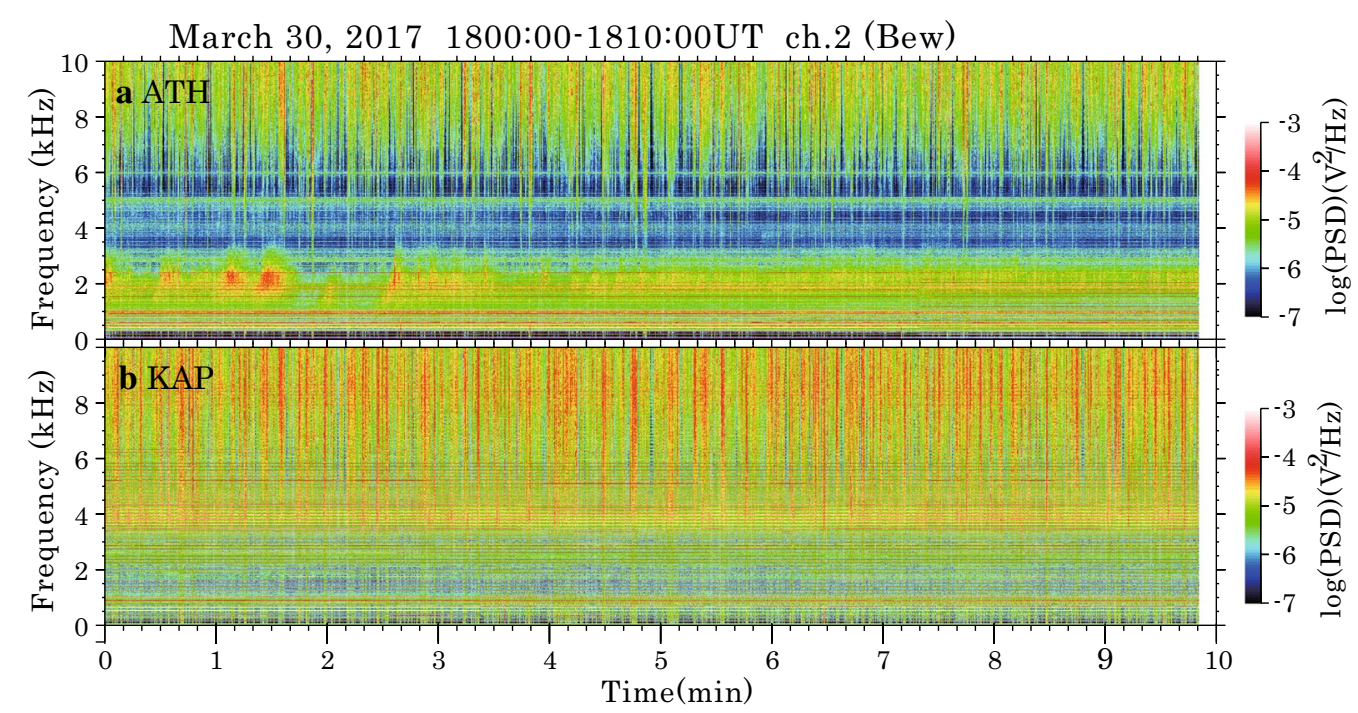

Fig. 15 Ten-minute spectra of ELF/NLF waves observed by loop antennas at ATH, and KAP

passes the prompt (microsecond to nanosecond lifetimes) blue and near-infrared emission lines of N2 and $\mathrm{N} 2+$. By using high transfer voltages during the transfer of electrons on the register, the EMCCD camera can amplify electrons on the CCD chip. Thus fast image sampling with low readout noise becomes possible for the EMCCD camera. The sampling rate of images is $100 \mathrm{~Hz}$, giving an opportunity to obtain one of the fastest images of low-intensity auroras. Every frame is triggered by the pulse signals from GPS-locked signal generator, which enables us to assure the accurate time stamp and to stabilize the $100 \mathrm{fps}$ data acquisition. The image resolution is $256 \times 256$ pixels (e.g., Kataoka et al. 2011). Three EMCCD cameras are installed at ATH, GAK, and KEV. The EMCCD cameras at KEV and GAK are used in collaboration with the Pulsating Aurora (PsA) Project (http://www.psa-research.org/english/), which provides two more EMCCD cameras in the northern Scandinavia region to cover a wide spatial area of the auroral oval.

Figure 16 shows an example of auroral image and north-south keograms obtained by the EMCCD camera at GAK on March 22, 2017, at 1307 UT (04 h MLT). Intense pulsating patches were observed around the center of the image at this time (Fig. 16a) during the recovery phase of a large substorm (maximum $\mathrm{AE}$ index (provisional) of $\sim 1000 \mathrm{nT}$ ) started at $11 \mathrm{UT}$. In the 1-min north-south keogram in Fig. 16b, auroral pulsations with periods of a few to $10 \mathrm{~s}$ are clearly seen. By focusing on the $10 \mathrm{~s}$ at 1307:20-1307:30 UT (Fig. 16c), we can see faster intensity modulation of these pulsating patches with a period of $\sim 0.3 \mathrm{~s}$, which indicates so-called $3-\mathrm{Hz}$ modulation of pulsating aurora due to interaction of high-energy electrons with magnetospheric ELF/ VLF emissions (e.g., Samara and Michell 2010; Miyoshi et al. 2015a, b, Nishiyama et al. 2016). Thus comparison of these EMCCD data with data from the loop antenna will be very interesting to investigate such a wave-particle interactions, though usually the magnetospheric ELF/VLF emissions are masked by the highly conductive ionosphere during pulsating aurora. Comparison of the EMCCD camera images of isolated proton aurora with EMIC waves observed by induction magnetometer will be more promising to study the interaction of highenergy ions and EMIC waves (e.g., Ozaki et al. 2016). Comparison with the Arase and Van Allen Probes satellites will be essential to study these wave-particle interaction processes by monitoring their spatial and temporal motion by using this ground EMCCD camera.

\section{Database construction}

Because the PWING project operates many instruments at many stations continuously, the amount of data becomes very large. Table 3 summarizes the amount of data produced by the PWING project for 5 years. The total amount of data except for those from the three EMCCD cameras is $331 \mathrm{~TB}$ for the 5 years. The EMCCD camera produces data of $670 \mathrm{~TB}$ per station, but we plan to abandon many of the EMCCD data with cloudy skies and no-aurora time to reduce the data amount. In total we expect that about $500 \mathrm{~TB}$ of data will be generated from a 5-year operation of the PWING instruments. The PWING project and PsA project operate a high-capacity (1 $\mathrm{PB})$ data storage facility at the ERG Science Center 


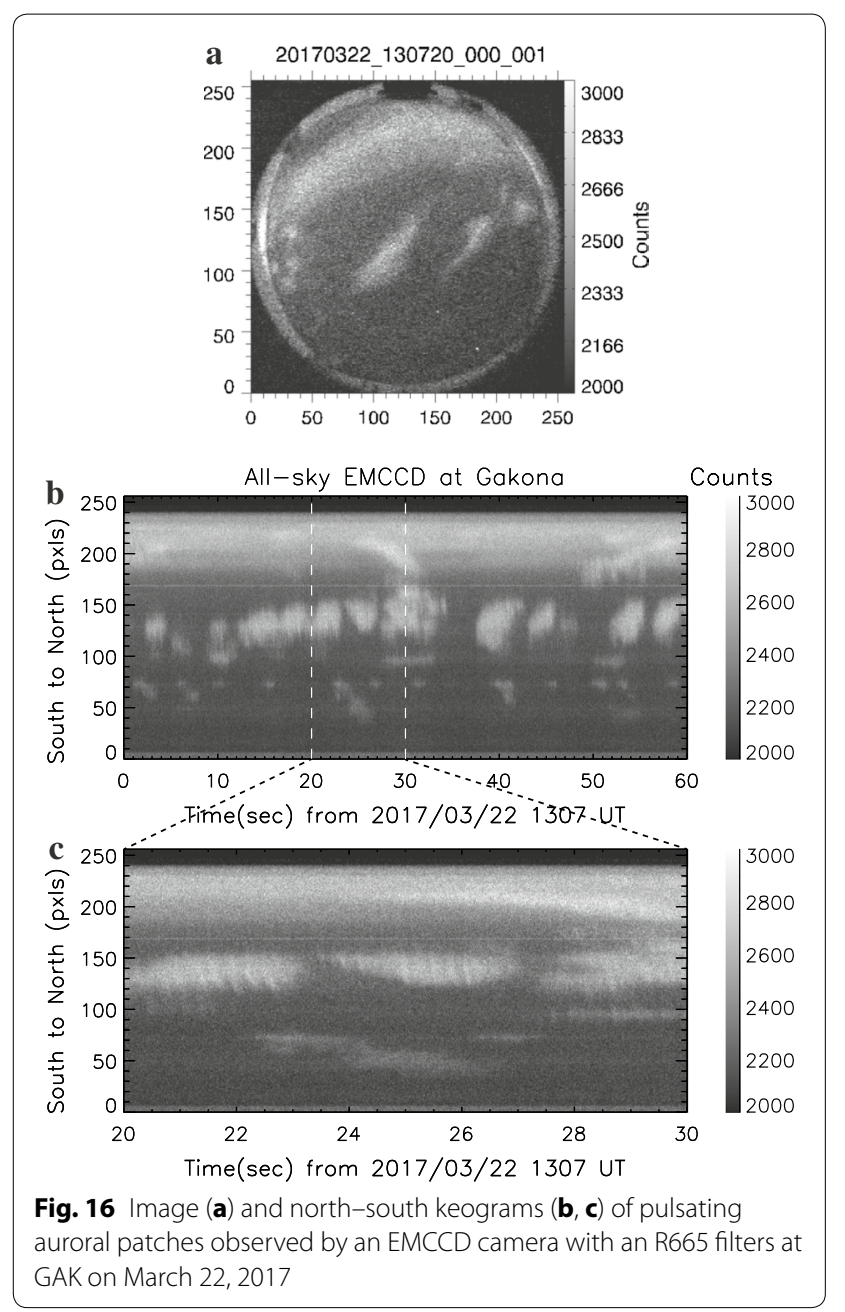

of ISEE, Nagoya University (http://ergsc.isee.nagoya-u. ac.jp) to store these data.

It is vitally important to prepare quick-look plots of the data just after the data acquisition at the site. The quicklook plots are used (1) to check whether the automated operation of the instruments is going correctly or not, and (2) to find interesting events in the data, and (3) to make it easy to compare different types of data. Quicklook plots of all the five types of instruments in the PWING project are prepared and opened on the Web site, which is linked to the PWING Web site at http:// www.isee.nagoya-u.ac.jp/dimr/PWING/en/.

In addition to these quick-look plots, the real data that can be used for data analysis are provided through the ERG Science Center in Common Data Format (CDF) (Miyoshi et al. 2017b, this issue). The information on the instruments and stations are also registered into the metadata database built by the inter-university upper atmosphere global observation network (IUGONET) project at http://www.iugonet.org/ (Hayashi et al. 2013). The ERG Science Center and the IUGONET project also provides data analysis tools for these PWING groundbased data based on the framework of the Space Physics Environment Data Analysis Software (SPEDAS) written in IDL (Angelopoulos 2008). These fruitful database facilities and frameworks allow us to make the data open to the international community and to stimulate collaborative researches with other related projects.

\section{Summary}

The PWING project was started in April 2016. The five types of instruments, i.e., all-sky airglow/aurora imagers, induction magnetometers, riometers, loop antennas, and EMCCD cameras were deployed mostly during the fiscal year of 2016 (April 2016 - March 2017) and started their automatic operation by March 22, 2017, except for the instruments at Nain, and all-sky imagers, riometers, and loop antennas at two Russian stations. The all-sky imagers measure invisible auroral/airglow emissions which correspond to electron and ion precipitations at low to middle energy ranges from eV to $10 \mathrm{keV}$. The riometers measure electron precipitation at a high energy range of 30-100 keV. The EMCCD cameras provide

Table 3 Data amount from the PWING instruments

\begin{tabular}{lllllll}
\hline Instrument & 1 data size (Byte) & Sampling (Hz) & Per day (MB) & Per month (GB) & Per year (TB) & 5 years (TB) \\
\hline All-sky camera & 552,000 & 0.03 & 715.3920 & 14.3078 & 0.1717 & 0.8585 \\
VLF antenna (2ch + GPS) & 6 & 40,000 & $20,736.0000$ & 642.8160 & 7.7138 & 38.5690 \\
VLF spectra (2ch) & $5,700,000$ & $1 / 600$ & 820.8000 & 25.4448 & 0.3053 & 1.5267 \\
Induction magnetometer (2ch + GPS) & 6 & 64 & 33.1776 & 1.0285 & 0.0123 & 0.0617 \\
Riometer (1ch, merged with magne) & 2 & 64 & 11.0592 & 0.3428 & 0.0041 & 0.0206 \\
Riometer (raw, QDC, CAN in ascii) & 37 & 64 & 204.5952 & 6.3425 & 0.0761 & 0.3805 \\
Total per station & & & $22,521.0240$ & 690.2824 & 8.2834 & 41.4169 \\
For 8 stations & & 100 & 360,000 & $11,160.0000$ & 66.2671 & 331.3356 \\
EMCCD camera (per station) & 100,000 & 100.9200 & 669.6000 \\
\hline
\end{tabular}


fast auroral images with a sampling rate of $100 \mathrm{~Hz}$. The induction magnetometers measure Pc1/EMIC waves at frequencies of the order of $\mathrm{Hz}$, which are related to the ion cyclotron instabilities. The loop antennas measure magnetospheric ELF/VLF emissions at frequencies of $\mathrm{kHz}$, which are related to electron cyclotron instabilities. Quick-look plots and real-data/metadata database have been constructed together with the analysis tools by the ERG Science Center and IUGONET on the SPEDAS framework, in order to make the data open to the international community and to stimulate collaborative research with related projects.

The PWING instruments are longitudinally distributed around the north geomagnetic pole at subauroral latitudes of $\sim 60^{\circ}$ MLAT $(L \sim 4)$ and provide a new opportunity to investigate local time/longitudinal extent of these particles and waves in the inner magnetosphere. By combining this longitudinal ground network with the in situ measurements of particles and waves in the equatorial plane of the magnetosphere by Arase and Van Allen Probes and with global modeling efforts, we can investigate energization and loss of the particles in the inner magnetosphere in a quantitative way. The quantitative understanding of plasma dynamics in the inner magnetosphere will also contribute to the safe and secure use of geospace around the Earth.

\begin{abstract}
Abbreviations
A/D: analogue-to-digital; ATH: Athabasca; CCD: charge-coupled device; CDF: common data format; CGM: corrected geomagnetic coordinates; CNA: cosmic noise absorption; ELF: extremely low frequency; EMCCD: electron multiplying charge-coupled device; EMIC: electromagnetic ion cyclotron; ERG: energization and radiation in geospace; FMI: Finnish Meteorological Institute; GAK: Gakona; GI-UAF: Geophysical Institute, University of Alaska Fairbanks; GPS: Global Positioning System; HUS: Husafell; IDL: interactive data language; IKFIA: Yu.G. Shafer Institute of Cosmophysical Research and Aeronomy, Siberian Branch of the Russian Academy of Sciences, Russian Federation; ISEE: Institute for Space-Earth Environmental Research; IST: Istok; ISTP: Institute of Solar-Terrestrial Physics, Siberian Branch of the Russian Academy of Sciences, Russian Federation; IUGONET: Inter-university Upper Atmosphere Global Observation Network; JSPS: Japan Society for the Promotion of Science; JYV: Jyväskylä; KAN: Kannuslehto; KAP: Kapuskasing; KEV: Kevo; LEMI: Laboratory of Electromagnetic Innovations; MAM: Maimaga; MEXT: Ministry of Education, Culture, Sports, Science and Technology; MLAT: magnetic latitude; MLON: magnetic longitude; MLT: magnetic local time; NAI: Nain; NICT: National Institute of Information and Communications Technology; NIPR: National Institute of Polar Research; NUR: Nurmijärvi; NYR: Nyrölä; OMTIs: optical mesosphere thermosphere imagers; OS: operating system; PC: personal computer; PiB: Pi burst; PPS: pulse per second; PSA project: Pulsating Aurora project; PWING: study of dynamical variation of particles and waves in the inner magnetosphere using ground-based network observations; QDC: quiet-day curve; SAR arc: stable auroral red arc; SGO: Sodankylä Geophysical Observatory; SPEDAS: Space Physics Environment Data Analysis Software; SuperDARN: Super Dual Auroral Radar Network; TBD: to be determined; ULF: ultra-low frequency; UPS: uninterruptible power supply; UT: universal time; VLF: very low frequency; ZGN: Zhigansk.
\end{abstract}

\section{Authors' contributions}

KS took a lead of the PWING project as the representative scientist and developed the all-sky imagers and induction magnetometers. YK, YH, YY, and TA supported the development and operations of the PWING instruments as technicians of Nagoya University. MO took a lead of the development and installation of the loop antennas. S-IO took a lead of the installation of the instruments at NYR, GAK, and KEV. MN supported the instrumentation at KAP and NAl and the calibration of the induction magnetometer. TN provided the $\mathrm{NICT}$ induction magnetometers and contributed to the deployment of the instrument at KAP and GAK. YT took a lead of the development and installation of the riometers. YO takes care of all the data collection from remote sites to Japan. YM and RK took a lead of the development and installation of the EMCCD cameras. YT studies the SAR arcs using the all-sky imagers and made Fig. 5. YT studies the magnetospheric ELF/NLF emissions and made Figs. 12 and 13. AS is a PD fellow of the PWING project and contributes the installation at GAK and the IUGONET metadata database. SK is a PD fellow of the PWING project and takes a lead for the CDF database construction. TH was and NT is PD fellows of the PWING project and contribute to the comparison of the PWING ground-based data with plasma convection models and the SuperDARN radar data. NN contributed to the deployment of instruments at IST. IS is the Project Manager of the Arase mission and contributes from the start of the PWING project with YM, the Arase Project Scientist. FT contributed to the PWING project with his LF radio wave receiver at ATH and MAM. YO supported the deployment of instruments at NAI and KAP. SS supported the deployment of instruments at KAP, and the development of the image-processing software for the all-sky imagers. KS contributed from the start of the PWING project and takes a lead for the modeling development for the PWING project. AK took a lead of the operation of the instruments at HUS. KH took a lead to develop the software for conjunction between Arase and PWING stations, as well as contributed to the data analysis of the EMCCD camera. YO contributes coordination of the EMCCD cameras at the Scandinavian stations including KEV and with the EISCAT radar. MC operates the Athabasca University Geophysical Observatory where all the PWING instruments at ATH are installed. JM Ruohoniemi supports the deployment and operations of the instruments at KAP. ME supports the deployment and operations of the instruments at NAI. ET, TU, JM (KAN loop antenna), TR and AK contributed to the deployment and operation of the instruments of the $\mathrm{SGO}$ stations. $\mathrm{AO}, \mathrm{MB}$, KK, and JM contributed to the deployment and operation of the instruments at NYR and KEV. DB is in charge of the deployment and operation of the instruments at ZGN and MAM. VK, AO, $A P, R V$, and RR contribute to the deployment and operation of the instruments at IST. WB and MK contributed to the deployment and operation of the instruments at GAK. All authors read and approved the final manuscript.

\section{Author details}

${ }^{1}$ Institute for Space-Earth Environmental Research, Nagoya University, Nagoya 464-8601, Japan. ${ }^{2}$ Kanazawa University, Kakuma-machi, Kanazawa 920-1192, Japan. ${ }^{3}$ Kyoto University, Oiwake-cho, Kitashirakawa, Sakyo-ku, Kyoto 606-8502, Japan. ${ }^{4}$ National Institute of Information and Communications Technology, 4-2-1 Nukui-kita, Koganei, Tokyo 184-8795, Japan. ${ }^{5}$ National Institute of Polar Research, Midori-cho 10-3, Tachikawa, Tokyo 190-8518, Japan. ${ }^{6}$ Institute of Space and Astronautical Science, Japan Aerospace Exploration Agency, Sagamihara, Japan. ${ }^{7}$ Graduate School of Science, Tohoku University, 6-3, Aramaki Aza-Aoba, Aoba-ku, Sendai 980-8578, Japan. ${ }^{8}$ Osaka ElectroCommunication University, Neyagawa, Japan. ${ }^{9}$ Aichi University, Toyohashi, Japan. ${ }^{10}$ University of Tokyo, 7-3-1 Hongo, Bunkyo-ku, Tokyo 113-0033, Japan. ${ }^{11}$ The University of Electro-Communications, Chofugaoka 1-5-1, Chofu, Tokyo 182-8585, Japan. ${ }^{12}$ Observatories, Athabasca University, 1 University Drive, Athabasca, AB T9S 3A3, Canada. ${ }^{13}$ Bradley Department of Computer and Electrical Engineering, Space@VT, Virginia Tech, 1901 Innovation Drive, Suite 1033, Blacksburg, VA 24060-6837, USA. ${ }^{14}$ Department of Physics, Augsburg University, 2211 Riverside Avenue, Minneapolis, MN 55454-1338, USA. ${ }^{15}$ Sodankylä Geophysical Observatory, University of Oulu, Tähteläntie 62,99600 Sodankylä, Finland. ${ }^{16}$ Astronomical Association Jyväskylän Sirius, Jyväskylä, Finland. ${ }^{17}$ Finnish Meteorological Institute, Erik Palmenin aukio 1, 00560 Helsinki, Finland. ${ }^{18}$ Yu.G.Shafer Institute of Cosmophysical Research and Aeronomy (IKFIA), Siberian Branch of the Russian Academy of Sciences, 31 , Lenin Ave., Yakutsk, Russia $677980 .{ }^{19}$ Institute of Solar-Terrestrial Physics (ISTP), Siberian Branch of the Russian Academy of Sciences, 126 a, Lermontov Str., Irkutsk, Russia $664033 .{ }^{20}$ Geophysical Institute, University of Alaska Fairbanks, Fairbanks, AK, USA.

\section{Acknowledgements}

The PWING project is mainly funded as the Grant-in-Aid for Specially Promoted Research (16H06286) by the Japan Society for the Promotion of Science (JSPS) and the Ministry of Education, Culture, Sports, Science and 
Technology (MEXT). The database construction of the PWING project has been supported by the ERG Science Center and the IUGONET project. This work was also supported by JSPS Grants-in-Aid for Scientific Research (20244080, 23403009, and 25247080, 15H05747, and 15H05815). Construction and operation of the facilities of Athabasca University Geophysical Observatory are supported by the Canada Foundation for Innovation, and we thank Kyle Reiter and lan Schofield for dedicated technical support at ATH. Construction of the PWING site at Kapuskasing was assisted by the Virginia Tech SuperDARN group supported under NSF award AGS-1341918. We appreciate Aleshkov Victor for his hard works to maintain operability of the Istok station.

\section{Competing interests}

The authors declare that they have no competing interests.

\section{Availability of data and materials}

All the data obtained by the PWING project are opened through ISEE, Nagoya University. Details can be found from the PWING Web site at https://www.isee. nagoya-u.ac.jp/dimr/PWING/en. Digital data are available through the ERG Science Center of ISEE, Nagoya University (https://ergsc.isee.nagoya-u.ac.jp/ index.shtml.en). The ELFNLF wave data obtained at KAN are available at the Sodankyla Geophysical Observatory, University of Oulu, Finland.

\section{Funding}

The PWING project is funded as the Grant-in-Aid for Specially Promoted Research (16H06286) by the Japan Society for the Promotion of Science (JSPS) and the Ministry of Education, Culture, Sports, Science and Technology (MEXT). This work is also supported by JSPS Grants-in-Aid for Scientific Research (20244080, 23403009, and 25247080, 15H05747, and 15H05815).

\section{Publisher's Note}

Springer Nature remains neutral with regard to jurisdictional claims in published maps and institutional affiliations.

Received: 4 September 2017 Accepted: 14 November 2017

Published online: 28 November 2017

\section{References}

Abel B, Thorne RM (1998) Electron scattering loss in Earth's inner magnetosphere 1. Dominant physical processes. J Geophys Res 103:2385-2396

Adachi T, Takashashi Y, Ohya H, Tsuchiya F, Yamashita K, Yamamoto M, Hashiguchi H (2009) Monitoring of lightning activity in southeast Asia: scientific objectives and strategies. Kyoto working papers on area studies, 13

Angelopoulos V (2008) The THEMIS mission. Space Sci Rev 141:5-34

Baker DN (2000) The occurrence of operational anomalies in spacecraft and their relationship to space weather. IEEE Trans Plasma Sci 28:2007-2016

Baker DN, Blake JB, Klebesadel RW, Higbie PR (1986) Highly relativistic electrons in the Earth's outer magnetosphere, 1, lifetimes and temporal history 1979-1984. J Geophys Res 91:4265

Carpenter DL (1966) Whistler studies of the plasmapause in the magnetosphere: 1. Temporal variations in the position of the knee and some evidence on plasma motions near the knee. J Geophys Res 71:693-709. https://doi.org/10.1029/JZ071i003p00693

Elkington SR, Hudson MK, Chan AA (1999) Acceleration of relativistic electrons via drift-resonant interaction with toroidal-mode PC-5 ULF oscillations. Geophys Res Lett 26:3273-3276

Engebretson MJ et al (2015) Van Allen Probes, NOAA, GOES, and ground observations of an intense EMIC wave event extending over $12 \mathrm{~h}$ in magnetic local time. J Geophys Res Space Phys 120:5465-5488. https:// doi.org/10.1002/2015JA021227

Fraser B (1975) lonospheric duct propagation and PC1 pulsation sources. J Geophys Res 80(19):2790-2796

Hayashi H, Koyama Y, Hori T, Tanaka Y, Abe S, Shinbori A, Kagitani M, Kouno T, Yoshida D, UeNo S, Kaneda N, Yoneda M, Umemura N, Tadokoro H, Motoba T (2013) Inter-university upper atmosphere global observation network (IUGONET). Data Sci J 12:WDS179-WDS184. https://doi. org/10.2481/dsj.WDS-030
Jun C-W, Shiokawa K, Connors M, Schofield I, Poddelsky I, Shevtsov B (2014) Study of Pc1 pearl structures observed at multi-point ground stations in Russia, Japan, and Canada, Earth Planet. Space 66:1-14

Jun C-W, Shiokawa K, Connors M, Schofield I, Poddelskiy I, Shevtsov B (2016) Possible generation mechanisms for Pc1 pearl structures in the ionosphere, based on 6 years of ground observations in Canada, Russia, and Japan. J Geophys Res. https://doi.org/10.1002/2015JA022123

Kataoka R, Miyoshi Y, Sakanoi T, Yaegashi A, Ebihara Y, Shiokawa K (2011) Ground-based multispectral high-speed imaging of flickering aurora. Geophys Res Lett 38:L14106. https://doi.org/10.1029/2011GL048317

Kawamura M, Kuwashima M, Toya T (1981) Comparative study of magnetic PC1 pulsations between low latitudes and high latitudes: source region and propagation mechanism of the waves deduced from the characteristics of the pulsations at middle and low latitudes. In: Nagata T (ed) The third symposium on coordinated observations of the ionosphere and the magnetosphere in the polar regions, Memoirs of National Institute of Polar Research Special Issue, vol 18. National Institute of Polar Research, Tokyo, pp 83-100

Kennel CF, Petschek HE (1966) Limit on stably trapped particle fluxes. J Geophys Res. 71(1):1-28

Li W, Bortnik J, Thorne R, Angelopoulos V (2011) Global distribution of wave amplitudes and wave normal angles of chorus waves using THEMIS wave observations. J Geophys Res 116:A12205. https://doi. org/10.1029/2011JA017035

Manninen J (2005) Some aspects of ELF-VLF emissions in geophysical research. PhD thesis, University of Oulu, Oulu, Finland

Martinez-Calderon K et al (2016) ELF/NLF wave propagation at subauroral latitudes: conjugate observation between the ground and Van Allen Probes A. J Geophys Res. https://doi.org/10.1002/2015JA022264

Mauk BH, Fox NJ, Kanekal SG, Kessel RL, Sibeck DG, Ukhorskiy A (2013) Science objectives and rationale for the Radiation Belt Storm Probes mission. Space Sci Rev 179:3-27. https://doi.org/10.1007/s11214-012-9908-y

Miyoshi Y, Morioka A, Obara T, Misawa H, Nagai T, Kasahara Y (2003) Rebuilding process of the outer radiation belt during the November 3, 1993, magnetic storm-NOAA and EXOS-D observations. J Geophys Res 108(A1):1004. https://doi.org/10.1029/2001JA007542

Miyoshi Y, Sakaguchi K, Shiokawa K, Evans D, Albert J, Connors M, Jordanova V (2008) Precipitation of radiation belt electrons by EMIC waves, observed from ground and space. Geophys Res Lett 35:L23101. https://doi. org/10.1029/2008GL035727

Miyoshi Y, Oyama S, Saito S, Fujiwara H, Kataoka R, Ebihara Y, Kletzing C, Reeves G, Santolik O, Cliverd M, Rodger C, Turunen E, Tsuchiya F (2015a) Energetic electron precipitation associated with pulsating aurora: EISCAT and Van Allen Probes observations. J Geophys Res. https://doi. org/10.1002/2014JA020690

Miyoshi Y, Saito S, Seki K, Nishiyama T, Kataoka R, Asamura K, Katoh Y, Ebihara Y, Sakanoi T, Hirahara M, Oyama S, Kurita S, Santolik O (2015b) Relation between energy spectra of pulsating aurora electrons and frequency spectra of whistler-mode chorus waves. J Geophys Res 120:7728-7736. https://doi.org/10.1002/2015JA021562

Miyoshi Y et al (2017a) Geospace exploration project ERG; overview. Earth Planets Space (this issue)

Miyoshi Y et al (2017b) The ERG Science Center. Earth Planets Space (this issue)

Nishiyama T, Miyoshi Y, Katoh Y, Sakanoi T, Kataoka R, Okano S (2016) Substructures with luminosity modulation and horizontal oscillation in pulsating patch: principal component analysis application to pulsating aurora. J Geophys Res 121:2360-2373. https://doi.org/10.1002/2015JA022288

Nomura R, Shiokawa K, Pilipenko V, Shevtsov B (2011) Frequency-dependent polarization characteristics of PC1 geomagnetic pulsations observed by multipoint ground stations at low latitudes. J Geophys Res 116:A01204. https://doi.org/10.1029/2010JA015684

Nomura R, Shiokawa K, Sakaguchi K, Otsuka Y, Connors M (2012) Polarization of PC1/EMIC waves and related proton auroras observed at subauroral latitudes. J Geophys Res 117:A02318. https://doi.org/10.1029/201 1 JA017241

Nomura R, Shiokawa K, Omura Y, Ebihara Y, Miyoshi Y, Sakaguchi K, Otsuka Y, Connors M (2016) Pulsating proton aurora caused by rising tone Pc1 waves. J Geophys Res 121:1608-1618. https://doi. org/10.1002/2015JA021681 
Okano S, Kim JS (1987) Observations of a SAR-arc associated with an isolated magnetic substorm. Planet Space Sci 35:475-482

Omura Y, Furuya N, Summers D (2007) Relativistic turning acceleration of resonant electrons by coherent whistler mode waves in a dipole magnetic field. J Geophys Res 112:A06236. https://doi.org/10.1029/2006JA012243

Ozaki M, Yagitani S, Nagano I, Hata Y, Yamagishi H, Sato N, Kadokura A (2008) Localization of VLF ionospheric exit point by comparison of multipoint ground-based observation with full-wave analysis. Polar Sci 2(4):237-249

Ozaki M et al (2012) Observed correlation between pulsating aurora and chorus waves at Syowa Station in Antarctica: a case study. J Geophys Res 117:A08211. https://doi.org/10.1029/2011JA017478

Ozaki M et al (2016) Fast modulations of pulsating proton aurora related to subpacket structures of Pc1 geomagnetic pulsations at subauroral latitudes. Geophys Res Lett. https://doi.org/10.1002/2016GL070008

Rees MH, Roble RG (1975) Observations and theory of the formation of stable auroral red arcs. Rev Geophys Space Phys 13:201-242

Reeves GD et al (2013) Electron acceleration in the heart of the Van Allen radiation belts. Science 341 (6149):991-994. https://doi.org/10.1126/ science. 1237743

Sakaguchi K, Shiokawa K, leda A, Miyoshi Y, Otsuka Y, Ogawa T, Connors M, Donovan EF, Rich FJ (2007) Simultaneous ground and satellite observations of an isolated proton arc at subauroral latitudes. J Geophys Res 112:A04202. https://doi.org/10.1029/2006JA012135

Sakaguchi K, Shiokawa K, Miyoshi Y, Otsuka Y, Ogawa T, Asamura K, Connors M (2008) Simultaneous appearance of isolated auroral arcs and Pc 1 geomagnetic pulsations at subauroral latitudes. J Geophys Res 113:A05201. https://doi.org/10.1029/2007JA012888

Sakaguchi K, Miyoshi Y, Spanswick E, Donovan E, Mann IR, Jordanova V, Shiokawa K, Connors M, Green JC (2012) Visualization of ion cyclotron wave and particle interactions in the inner magnetosphere via THEMIS-ASI observations. J Geophys Res 117:A10204. https://doi. org/10.1029/2012JA018180

Samara M, Michell RG (2010) Ground-based observations of diffuse auroral frequencies in the context of whistler mode chorus. J Geophys Res 115:A00F18. https://doi.org/10.1029/2009JA014852

Seki K, Miyoshi Y, Ebihara Y, Katoh Y, Amano T, Shoji M, Nakamizo A, Keika K, Hori T, Nakano S, Watanabe S, Kamiya K, Takahashi N, Omura Y, Nose M, Fok M-C, Tanaka T, leda A, Yoshikawa A (2017) Theory, modeling, and integrated studies in the Arase (ERG) project. Earth Planets Space (this issue)
Shiokawa K, Katoh Y, Satoh M, Ejiri MK, Ogawa T, Nakamura T, Tsuda T, Wiens RH (1999) Development of optical mesosphere thermosphere imagers (OMTI). Earth Planets Space 51:887-896. https://doi.org/10.1186/ BF03353247

Shiokawa K, Katoh Y, Satoh M, Ejiri MK, Ogawa T (2000) Integrating-sphere calibration of all-sky cameras for nightglow measurements. Adv Space Sci 26:1025-1028

Shiokawa K, Otsuka Y, Ogawa T (2009a) Propagation characteristics of nighttime mesospheric and thermospheric waves observed by optical mesosphere thermosphere imagers at middle and low latitudes. Earth Planets Space 61:479-491. https://doi.org/10.1186/BF03353165

Shiokawa K, Hosokawa K, Sakaguchi K, leda A, Otsuka Y, Ogawa T, Connors M (2009b) The optical mesosphere thermosphere imagers (OMTIs) for network measurements of aurora and airglow. In: Hirahara M, Miyoshi Y, Terada N, Shinohara I, Mukai T (eds) Future perspectives of space plasma and particle instrumentation and international collaborations, AIP conference proceedings, pp 212-215. https://doi.org/10.1063/1.3169292

Shiokawa K et al (2010) The STEL induction magnetometer network for observation of high-frequency geomagnetic pulsations. Earth Planets Space 62:517-524. https://doi.org/10.5047/eps.2010.05.003

Shoji M, Omura Y (2012) Precipitation of highly energetic protons by helium branch electromagnetic ion cyclotron triggered emissions. J Geophys Res 117:A12210. https://doi.org/10.1029/2012JA017933

Summers D, Thorne RM (2003) Relativistic electron pitch-angle scattering by electromagnetic ion cyclotron waves during geomagnetic storms. J Geophys Res 108(A4):1 143. https://doi.org/10.1029/2002JA009489

Summers D, Thorne RM, Xiao F (1998) Relativistic theory of wave-particle resonant diffusion with application to electron acceleration in the magnetosphere. J Geophys Res 103:20487-20500. https://doi. org/10.1029/98JA01740

Wang D et al (2015) Statistical characteristics of EMIC waves: Van Allen Probe observations. J Geophys Res 120:4400-4408. https://doi. org/10.1002/2015JA021089

Yonezu Y, Shiokawa K, Connors M, Ozaki M, Manninen J, Yamagishi H, Okada M (2017) Simultaneous observations of magnetospheric ELFNLF emissions in Canada, Finland, and Antarctica. J Geophys Res. https://doi.org/10.100 2/2017JA024211

\section{Submit your manuscript to a SpringerOpen ${ }^{\circ}$ journal and benefit from:}

- Convenient online submission

- Rigorous peer review

- Open access: articles freely available online

- High visibility within the field

- Retaining the copyright to your article

Submit your next manuscript at $\mathbf{s p r i n g e r o p e n . c o m ~}$ 